\title{
A INTELIGÊNCIA ARTIFICIAL E O ECOSSISTEMA INDUSTRIAL NO CONTEXTO PANDÊMICO: UMA ABORDAGEM JURÍDICA E ANTROPOCÊNTRICA DO ATUAL DESAFIO DAS PATENTES NA ÁREA DA SAÚDE SOB O PARADIGMA EUROPEU
}

\author{
ARTIFICIAL INTELLIGENCE AND THE INDUSTRIAL \\ ECOSYSTEM IN THE PANDEMIC CONTEXT: A LEGAL AND \\ ANTHROPOCENTRIC APPROACH TO THE CURRENT CHALLENGE \\ OF HEALTH PATENTS UNDER THE EUROPEAN PARADIGM
}

Gabrielle Bezerra Sales Sarlet

Cristina Maria de Gouveia Caldeira

\section{RESUMO}

Mediante investigação bibliográfica, exploratória por meio do emprego do método hipotético-dedutivo, analisa-se os principais desafios suscitados pela aplicação da inteligência artificial e do big data em tempos de Covid-19, refletindo-se sobre o equilíbrio necessário entre custos e benefícios da atribuição de patentes e a garantia do acesso a medicamentos inovadores, em especial no contexto europeu, bem como, a inovação e a sustentabilidade da indústria farmacêutica europeia. Analisa-se o processo da implementação da inteligência artificial em conformidade com a política de proteção dos dados relativos à saúde e aos dados genéticos, à luz dos instrumentos jurídicos no paradigma do direito europeu.

Palavras-chave: Inteligência Artificial. Dados pessoais naárea dasaúde. Patentes. 


\begin{abstract}
Through bibliographical research, exploratory through the use of the hypothetical-deductive method, the main challenges raised by the application of artificial intelligence and big data in times of Covid-19 are analyzed, reflecting on the necessary balance between costs and benefits of granting patents and ensuring access to innovative medicines, especially in the European context, as well as the innovation and sustainability of the European pharmaceutical industry. The process of implementation of artificial intelligence is analyzed in accordance with the policy of protection of data related to health and genetic data, in the light of legal instruments in the paradigm of European law
\end{abstract}

Keywords: Artificial Intelligence. Health person data. Patents.

\title{
APORTES INTRODUTÓRIOS
}

Definida como "um conjunto de tecnologias que combinam dados, algoritmos e capacidade computacional”1, a inteligência artificial (doravante IA) se expressa por meio de máquinas que mimetizam "certas funções cognitivas que são caraterísticas da mente humana” (VICENTE, 2020, p. 93-105), distinguindo-se em forte e fraca, dependendo da sua complexidade. Aplica-se em sistemas que apresentam um comportamento inteligente, capazes de analisar o ambiente e tomar medidas, com um determinado nível de autonomia, de modo a atingir objetivos específicos, cobrindo várias áreas, desde os motores de busca, os assistentes pessoais e outros, veículos automatizados, robôs e até às armas autónomas. Este crescimento tão acentuado é indissociável dos avanços em data science (ciência de dados), baseando-se cada vez mais em métodos de aprendizagem automática, treinados com grande quantidade de dados.

Um dos fatores que contribuíram para o seu crescimento, a par da grande quantidade de dados, foi o desenvolvimento de métodos de treino de redes neuronais profundas que promovem o reconhecimento da fala, da imagem, bem como da capacidade de detectar, de modelar ou de exibir comportamentos afetivos como emoções, humor, atitudes e personalidades dando os primeiros passos na direção dos sistemas inteligentes dotados de capacidade social e eventualmente de certa moralidade, a inteligência artificial e emocional. 
A IA entrou em uma nova era, graças à convergência de fatores como o aumento da capacidade computacional, a multiplicação dos conjuntos de dados e a evolução dos algoritmos ${ }^{2}$, transformando-se em uma das áreas de investigação científica multidisciplinar mais complexas, atual e promissora. De fato, a dificuldade em prever o comportamento de produtos dotados de IA, bem como de compreender as possíveis causas de danos, levou a Comissão Europeia e Portugal, enquanto Presidente do Conselho da União Europeia(UE) ${ }^{3}$, a se concentrarem na elaboração da primeira lei sobre IA. Esse pioneirismo justifica, destarte, a atual investigação, a qual intenta compreender esse cenário, contribuindo para adensamento de parâmetros, para além do âmbito tecnológico, mais seguros e confiáveis.

A propósito, a criação de uma iniciativa legislativa para enquadrar a IA encontra-se mencionada no "Relatório sobre as implicações em matéria de segurança e de responsabilidade decorrentes da inteligência artificial, da Internet das coisas e da robótica", apresentado pela Comissão Europeia, no dia 19 de fevereiro de 2020. Nesse Relatório, é referido que as grandes quantidades de dados envolvidos, a dependência de algoritmos e a opacidade do processo decisório dos sistemas de inteligência artificial tornam mais difícil prever o comportamento de produtos com inteligência artificial e, de todo modo, compreender as possíveis causas de danos ${ }^{4}$. Interessa apontar que a dependência de algoritmos e a opacidade do processo decisório dos sistemas de IA estão na base da decisão de criar um instrumento jurídico europeu para a inteligência artificial, em defesa da transparência e da concretização dos direitos humanos e fundamentais mediado pelo viés antropocêntrico (MARTINO, 2020, p. 46-7).

Diretamente vinculada ao emprego da IA, oportuno admitir, a robótica utilizada em vários setores da economia, é na saúde que tem um especial impacto, designadamente em: tratamento de doenças crónicas, diagnósticos radiológicos, automatização da análise de amostras clínicas e radiografias/exames bidimensionais, entre outros ${ }^{5}$.

Nessa perspectiva, destaca-se as recomendações do Parlamento Europeu, em que a Comissão Europeia fez emergir um "Plano Coordenado para a Inteligência Artificial" que acompanha o "Programa Horizonte Europa (2020-2027)”6 e o "Programa Europa Digital (2021-2027)", que financiam projetos em cinco domínios fundamentais: supercomputação, 


\section{inteligência artificial, cibersegurança, competências digitais} avançadas, e ampla utilização das tecnologias digitais em toda a economia e sociedade". Relevante ainda é o fato do "Programa Europa Digital (2021-2027)", viabilizar o "Plano de ação para a edução digital (2021-2027)”8, essencial à educação digital de elevada qualidade, inclusiva e acessível na Europa. Nesse plano, serão desenvolvidas orientações éticas em matéria de IA, bem como recomendações sobre a utilização de dados no ensino e na aprendizagem, para os educadores.

Em outra banda, a Comissão Europeia apresentou "A European Strategy for Data" ${ }^{9}$, tratando-se de medidas políticas e de investimentos para habilitar a economia de dados para os próximos cinco anos. Esta estratégia de dados é apresentada ao mesmo tempo que a "Shaping Europe's Digital Future" e o "White Paper on Artificial Intelligence"10. Estes documentos complementam-se. Conscientes dos desafios relacionados com a conectividade e armazenamento, a cibersegurança ${ }^{11}$ e a carência de competências digitais, a Comissão Europeia aponta a estratégia12 para os ultrapassar, fazendo pleno uso do forte quadro jurídico ${ }^{13}$ em vigor para emular um mercado único de dados em benefício de empresas, dos investigadores, da administração pública e dos cidadãos.

Recorda-se nessa altura que, em 2015, a Comissão Europeia apresentou, v.g., o "Mercado Único Digital”, consistindo em um pacote legislativo que veio colmatar a ausência de instrumentos supraestaduais de proteção do cidadão, ajustados à realidade internacional. Um ano depois, foi publicado o Regulamento Geral de Proteção de Dados (RGPD), publicado em 27 de abril de $2016^{14}$, a Diretiva de Cooperação Policial aprovada a 27 de abril de $2016^{15}$, o Regulamento da Cibersegurança em 2017, e a proposta de Regulamento de Privacidade Eletrónica ${ }^{16}$.

Em 2020, assim como os demais países, a Europa foi desafiada pelo SARS-CoV-2, um novo coronavírus identificado pela primeira vez em Wuhan, China, provocando a COVID-19 que se transformou em uma pandemia, reconhecida pela Organização Mundial de Saúde (OMS) ainda em março. Naquele momento, a ciência já se mobilizava para acelerar, inovar e otimizar as soluções terapêuticas. A crise de saúde pública advinda em função da COVID-19, obrigou a UE e os Estados-membros a enfrentar um desafio sem precedentes com impactos ${ }^{17}$ difusos. A Europa assumiu 
que nenhum Estado-membro podia ser bem-sucedido na luta contra a crise motivada pela COVID-19, agindo isoladamente, o que justificou um conjunto de medidas integradas, designado de "Espaço Europeu de Dados de Saúde" criado pela Comissão Europeia, em novembro de $2020^{18}$.

A resposta conjunta à pandemia levou à criação de relevantes instrumentos e de ações na área da saúde pública, que são aqui meramente enumerados: Regulamento (UE) 2020/1043 de 15 de julho de 2020, relativo à realização de ensaios clínicos com medicamentos para uso humano que contenham ou sejam constituídos por organismos geneticamente modificados destinados a tratar ou prevenir a doença do coronavírus (COVID-19) e ao fornecimento desses medicamentos; Diretiva (UE) 2020/2020 do Conselho de 7 de dezembro de 2020, no que diz respeito a medidas temporárias relativas ao imposto sobre o valor acrescentado aplicável às vacinas contra a COVID-19 e aos dispositivos médicos para diagnóstico in vitro desta doença em resposta à pandemia de COVID-19; Comunicação da Comissão sobre as estratégias de vacinação contra a COVID-19 e a disponibilização das vacinas; Recomendação (UE) 2020/1632 do Conselho de 30 de outubro de 2020, sobre uma abordagem coordenada das restrições à liberdade de circulação em resposta à pandemia de COVID-19 no espaço Schengen ${ }^{19}$.

Face à magnitude da crise, impunha-se uma resposta rápida e coordenada das instituições, para a aquisição das vacinas à escala europeia, bem como o seu acesso por parte de todos os Estadosmembros, configurando uma ação no domínio da saúde pública, "uma ação determinada de todos os Estados-Membros e das instituições e órgãos da UE, que são chamados a colaborar num verdadeiro espírito de solidariedade" 20 .

Em face desse contexto pandêmico que persiste, prenhe de questionamentos, intenta-se, mediante investigação bibliográfica, exploratória e utilizando o método hipotético-dedutivo, analisar os desafios à proteção de dados pessoais suscitados com o emprego da inteligência artificial e do big data em tempos de Covid-19, sobretudo com base no contexto europeu e tendo em vista o equilíbrio necessário entre os custos e os benefícios de atribuição de patentes e, paralelamente, a garantia ao acesso de medicamentos inovadores e acessíveis, bem como a preservação 
da competitividade, da inovação e da sustentabilidade da indústria farmacêutica europeia. Intenta-se, assim, clarificar o panorama atual em que se busca luminares para servir de molde para a realidade brasileira.

Investiga-se, para tanto, a implementação da inteligência artificial em conformidade com a política de proteção dos dados relativos à saúde e aos dados genéticos para, em sintonia com os instrumentos jurídicos de direito secundário europeu, procurar entender os esforços desenvolvidos pela União Europeia e pelas suas instituições de modo a assegurar a proteção dos direitos da pessoa humana face às novas tecnologias, em um momento radical para a Ciência, em que os cientistas maximizam o volume de dados atualmente gerado, bem como o uso de IA para oferecer inovação terapêutica.

Partindo de pilares éticos, busca-se analisar um modelo de enquadramento legal da IA baseado no equacionamento da confiança e do risco, ao tempo em que se faz apelo à convergência entre o direito de propriedade intelectual, os direitos humanos e fundamentais integrados em um ecossistema industrial, delineado por contornos jurídicos e civilizacionais. Nesse sentido, não se deve olvidar que o modelo europeu se projeta como um exemplo para outros países, inclusive servindo como aporte para o cenário brasileiro atual em virtude das similaridades e das conjugações de esforços na construção de um sistema protetivo que abrange os dados pessoais, sendo configurado com base na proteção multinível da pessoa humana.

\section{SAÚDE PÚBLICA NO DIREITO EUROPEU: BASE LEGAL}

A UE tem encetado um largo e profundo itinerário de proteção da saúde, desde as iniciais preocupações com a saúde dos trabalhadores até ao atual "elevado nível de proteção de saúde" que inclui a vigilância, o alerta e o combate contra as ameaças à Saúde Pública e o incentivo à cooperação entre os Estados-membros, a fim de aumentar a complementaridade dos seus serviços de saúde nas regiões transfronteiriças (CAMPOS, 2012, p. 711). Enquanto no Tratado de Maastricht (1992), a saúde pública surgia com um âmbito limitado, ainda assim estava criada uma base jurídica clara 
para a adoção de medidas de política de saúde, o Tratado de Amesterdão (1997), reforça essas disposições, mas é no Tratado de Lisboa, mais concretamente no artigo 168. do Tratado sobre o Funcionamento da União Europeia (TFUE), que se reforça a cooperação entre a União, os Estados-membros e as organizações internacionais competentes no domínio da saúde pública (no 3) ${ }^{21}$.

A melhoria da saúde pública, a prevenção das doenças e infeções humanas e a redução dos fatores de risco para a saúde física e mental faz parte da política da saúde da UE em complemento das políticas nacionais em observância do princípio da subsidiariedade, "as quais englobam a organização, a prestação e a gestão de serviços de saúde e de cuidados médicos, bem como a repartição dos recursos que lhes são afectados" (CAMPOS, 2012, 710).

Considerando que o direito ao mais elevado padrão de saúde física e mental constitui um direito humano, fundamental à proteção da saúde prevista na Carta dos Direitos Fundamentais da União Europeia (CDFUE), que no artigo 35. da CDFUE oferece a todas as pessoas "o direito de aceder à prevenção em matéria de saúde e de beneficiar de cuidados médicos, de acordo com as legislações e práticas nacionais. Na definição e na execução de todas as políticas e ações da União é assegurado um elevado nível de proteção da saúde humana".

Logo, dando cumprimento ao Tratado de Lisboa, a Europa tem tentado enfrentar de forma apropriada a pandemia. As autoridades sanitárias e de cuidados da Europa foram confrontadas com a COVID 19, um desafio comum, ao qual só uma ação conjunta poderia dar uma resposta adequada. Assim, e.g., no âmbito da "Estratégia da UE para as vacinas contra a COVID 19"22, a Comissão Europeia celebrou vários contratos com empresas fabricantes de vacinas, em nome de todos os Estados-membros, designados de "Acordos Prévios de Aquisição", "para acelerar o desenvolvimento, o fabrico e a disponibilização de vacinas contra a COVID-19"23.

No final de 2020, as vacinas contra a COVID-19, foram sendo disponibilizadas à medida que eram aprovadas pela Agência Europeia de Medicamentos (EMA). Dessa forma, para além de garantir o acesso às vacinas em toda a UE, a Comissão Europeia pretendeu distribuir 
as vacinas equitativamente pelos países mais carenciados, tornando a vacina um bem público mundial, assente em valores de universalidade, solidariedade e respeito mútuo, em linha com o terceiro objetivo da Agenda de Desenvolvimento Sustentável 2030 das Nações Unidas". ${ }^{24}$

Esta ação, não pode ser entendida como um ato isolado. Com efeito, a União Europeia tem vindo a fazer um caminho de proteção da Saúde, como anteriormente já o referimos. Importa recordar que a política europeia de saúde intentada em 1993, é precursora de programas plurianuais de saúde pública subsequentes ${ }^{25}$, a exemplo do atual "Programa EU4Health 2021-2027"26, que irá investir 9,4 mil milhões de euros no financiamento dos Estados-membros, de organizações de saúde e de ONGs. Em rigor, não custa advertir, que esses esforços em rede são determinantes para a questão alvo deste manuscrito.

\section{ORGANIZAÇÃO E PRESTAÇÃO DE CUIDADOS DE SAÚDE E A INTELIGÊNCIA ARTIFICIAL NO CONTEXTO PANDÉMICO}

O Tratado de Lisboa estipula que "na definição e execução de todas as políticas e ações da União será assegurado um elevado nível de proteção da saúde". Porém, a responsabilidade pela proteção da saúde e, em especial, pelos próprios sistemas de saúde continua a incumbir, em primeiro lugar, aos Estados-membros, tal como se prevê no no 7 do artigo 168. o do TFUE. Nessa conformidade, mesmo perante uma pandemia, à guisa de ilustração, cada Estado-membro tem direito à aquisição de uma quantidade determinada de vacinas contra a COVID-19, durante um determinado período e a um determinado custo, parcialmente financiado pelo "Instrumento de Apoio de Emergência". Assim se compreende que a Alemanha, a exemplo de outros países, já tenha adquirido autonomamente vacinas para a COVID19, e em Portugal há quem defenda a mesma prática.

Em Portugal, tal como os restantes Estados-membros, pelo menos em um primeiro momento, à exceção do desvio da Hungria ao adquirir a vacina russa, aderiu-se à aquisição de vacinas no âmbito do procedimento europeu centralizado. E nessa medida, por meio da Resolução do Conselho 
de Ministros n. ${ }^{-}$64-A/2020 de 20 de agosto, foi concedida uma autorização para a realização de despesa relativa à primeira fase dos procedimentos aquisitivos. Oportunamente, com vista à coordenação dos procedimentos junto à Comissão Europeia, foi criado um "Steering Board", no qual Portugal é representado pelo INFARMED - Autoridade Nacional do Medicamento e Produtos de Saúde, I. P.

Por sua vez, o contexto pandémico, veio provar que é imperioso "dispor de tecnologias ligadas à IA e de tecnologias conexas no domínio do reconhecimento remoto ou biométrico, como as aplicações de rastreio, enquanto nova forma de lidar com a COVID-19 e com eventuais crises sanitárias e de saúde pública que se apresentem no futuro, atendendo, simultaneamente, à necessidade de proteger os direitos fundamentais, o direito à vida privada e os dados pessoais (...)"27.

O "Plano Coordenado para a Inteligência Artificial"28 é um bom exemplo, ao pretender criar as condições que elevam o nível de proteção de saúde da UE, por meio da investigação, da inovação tecnológica e do reforço da cooperação transfronteiriça, atraindo para os seus projetos os investigadores, as universidades, as empresas, os centros de investigação e os laboratórios farmacêuticos nacionais e internacionais.

Cabe afirmar que a construção coletiva do conhecimento passa inevitavelmente pelo aumento da capacidade computacional, da disponibilidade de dados e da evolução dos algoritmos, que fazem da IA uma das tecnologias mais desafiantes e promissoras do século XXI. 0 cenário pandémico de COVID-19 tornou as inovações tecnológicas na área da saúde, ainda mais relevantes para a sociedade ${ }^{29}$, clarificando que a competição na indústria farmacêutica é impulsionada pelo conhecimento científico, e pela tutela das invenções, com especial destaque para as patentes (medicamentos e vacinas), o que implica em uma abordagem, ainda que resumida dos direitos industriais, com particular destaque para as patentes farmacêuticas (COECKELBERGH, 2020, p. 3), ressaltando-se que, em face da COVID-19, tornou-se absolutamente necessário uma abordagem europeia comum para a salvaguarda dos direitos humanos e fundamentais ${ }^{30} 31$.

A despeito do otimismo, a fiabilidade é de modo inconteste uma condição prévia para a sua aceitação" 32 . Com efeito, levantam-se várias 
questões de ordem legal, ético e filosófico em torno da tutela da privacidade, e em especial quanto à proteção da informação de saúde, contexto que motivou a proposta de um novo instrumento jurídico a apresentar ao longo de 2021, que deverá atender aos principais postulados éticos da IA e sobre os quais importa tecer algumas reflexões.

\section{OS PRINCIPAIS POSTULADOS ÉTICOS DA INTELIGÊNCIA ARTIFICIAL}

Os princípios éticos vão além dos aspetos legais (soft ethics), exigindose um agir baseado em valores, em direitos e na responsabilidade (hard ethics). Trata-se de uma ética capaz de moldar a legislação, designadamente o Regulamento (UE) 2016/679, de 27 de abril de 2016, Regulamento Geral de Proteção de Dados (RGPD), no sentido do seu aperfeiçoamento. Salienta-se que os direitos humanos e fundamentais estão ancorados na dignidade da pessoa humana e, constituem um porto de abrigo, um referencial ao qual já não se pode abdicar (CALDEIRA, 2020, p. 222-253). Estes referenciais, portanto, têm vindo a iluminar o iter traçado pela União Europeia, desde a "Estratégia Europeia para a Inteligência Artificial" (2018), à publicação do "Livro Branco para a Inteligência Artificial e a Estratégia para a Proteção de Dados" (2020), até ao "Espaço Europeu de Dadas de Saúde." (2020).

No Livro Branco, v.g., é referido que "a supervisão humana contribui para garantir que um sistema de IA não põe em causa a autonomia humana nem produz outros efeitos negativos. O objetivo de uma IA fiável, ética e centrada no ser humano só pode ser alcançado por meio da garantia de um envolvimento adequado dos seres humanos em aplicações de $\mathrm{IA}^{33}$, mormente as de alto risco ${ }^{34}$.

Para garantir a correta aplicação da IA, a Comissão Europeia criou em 2018, o Grupo de Peritos de alto nível sobre a IA (GPAN IA), composto por 52 especialistas, provenientes da academia, das empresas e da sociedade civil, com a missão de apoiar a implementação da estratégia europeia de inteligência artificial. No mesmo ano, o GPAN IA apresentou o primeiro projeto de orientações éticas, muito influenciado pelo Grupo Europeu de 
Ética para as Ciências e as Novas Tecnologias e pela Agência dos Direitos Fundamentais. Foi igualmente criado em 2018, a "Aliança Europeia para a IA", uma plataforma aberta que tem por objetivo reunir contributos para o grupo de peritos então criado. ${ }^{35}$

Em 2019, o GPAN IA apresentou o documento revisto, texto que foi bem acolhido pelos Estados-Membros, no qual defendem que uma "IA de confiança" só é alcançada se respeitar os valores europeus, que se baseiam no respeito pela dignidade humana, fundamento axiológico da EU, na liberdade, na democracia, na igualdade, no Estado de direito e no respeito pelos direitos humanos, previstos no artigo 2. ${ }^{\circ}$ do Tratado da União Europeia e na Carta dos Direitos Fundamentais da União Europeia (CDFUE). Estes direitos, princípios e valores devem ser observados ao longo do ciclo de vida do sistema de IA, atendendo a três componentes cruciais: a conformidade com a legislação; o respeito dos princípios éticos e; a robustez.

Concomitante com a UE, a OCDE enunciou um conjunto de princípios ${ }^{36}$ que devem nortear a aplicação da IA no interesse de resultados benéficos para as pessoas e para o planeta ${ }^{37}$. De igual modo, a OCDE defende que os princípios se complementam e devem ser considerados como um todo. Os mesmos princípios orientam os países da $\mathrm{OCDE}^{38} \mathrm{e}$ do G20, orientando igualmente a Bulgária, o Chipre, a Croácia e Malta, Estados-membros da União Europeia. Por último, a Albânia, a Andorra, a Armênia, o Azerbaijão, a Bósnia e Herzegovina, a Geórgia, o Liechtenstein, a Macedónia do Norte, a Moldávia, o Mónaco, o Montenegro, o San Marino, a Sérvia e a Ucrânia foram incluídos através do Conselho da Europa, que aprovou uma Recomendação CM/Rec(2020)1 do Comité de Ministros aos Estados Membros, sobre o impacto dos sistemas algorítmicos sobre os direitos humanos, a 8 de abril de 2020 .

Em suma, inúmeros países comprometem os seus governos aos Princípios da $O C D E$, que em muito se aproximam dos princípios apresentados pelo GPAN IA. no que se refere à essencialidade das decisões finais serem humanas, sempre que atinjam Direitos das pessoas naturais. Daí, ser possível fundamentar tais princípios na Declaração Universal dos Direitos Humanos e, guiados pelo pensamento de Norberto Bobbio, admite-se que: 
“[...] la manifestazione dell'unica prova con cui un sistema di valori può essere considerato umanamente fondato e quindi riconosciuto: e questa prova è il consenso generale circa la sua validità. I giusnaturalisti avrebbero parlato di 'consensus omnium gentium' o 'humani generis'. [até porque] "Non so se ci si rende conto sino a che punto la Dichiarazione universale rappresenti un fatto nuovo nella storia, in quanto per la prima volta nella storia un sistema di principi fondamentali della condotta umana è stato liberamente ed espressamente accettato, attraverso i loro rispettivi governi, dalla maggior parte degli uomini viventi sulla terra. Con questa dichiarazione un sistema di valori è (per la prima volta nella storia) universale, non di princĺpio ma di fatto, in quanto il consenso ulla sua validità e sulla sua idoneità a reggere le sorti della comunità futura di tutti gli uomini è stato esplicitamente dichiarato" 39,40 .

Sem impor uma hierarquia, o GPAN IA identificou sete princípios que se complementam ${ }^{41}$ e onde se incluem aspetos sistémicos, individuais e sociais. Convidados a testar a lista de avaliação criada pelo GPAN $\mathrm{IA}^{42}$, cada Estado membro pode intervir, comunicando informações sobre a forma de melhorar o ecossistema IA. Paralelamente a Comissão organizou atividades de sensibilização, permitindo ao GPAN IA apresentar as orientações para a IA junto dos Estados membros e em especial do setor da indústria e dos serviços.

Em virtude da Aliança Europeia da Inteligência Artificial e da AI4EU ${ }^{43}$, foi realizada em 2020, uma atualização das orientações, que devem constituir a base do quadro jurídico operacional para o desenvolvimento de uma IA europeia e de políticas públicas, contribuindo dessa forma para a construção de um quadro de cooperação global que assegure a fiabilidade da IA e que garanta a integridade dos direitos humanos e fundamentais. Consciente do impacto que a IA pode ter na sociedade civil, bem como das suas implicações humanas e éticas, a Comissão Europeia defende a melhor utilização de grandes volumes de dados para a inovação ${ }^{44}$. É com esse objetivo que apoia uma abordagem regulamentar orientada para o investimento na IA, que regule os riscos associados a determinadas utilizações desta nova tecnologia ${ }^{45}$ e, consequentemente, que se baseie nos valores europeus e nos direitos humanos e fundamentais, destacandose inclusive a proteção da privacidade ${ }^{46}$. 
Cumpre aferir, em vista a profunda transformação da sociedade, se por um lado, faz crescer a tensão entre a evolução tecnológica e a regulação, por outro lado, faz apelo a novos compromissos éticos (ANTUNES, 2020, p. 7) na medida em que se cristaliza que a Europa pretende aumentar a confiança em uma IA centrada no ser humano e baseada em princípios ${ }^{47}$. De qualquer sorte, existe consenso entre as instituições europeias em torno da necessidade do quadro regulamentar da inteligência artificial. Nessa conformidade, o Parlamento Europeu aprovou uma Resolução com a iniciativa legislativa "Regime relativo aos aspetos éticos da inteligência artificial, da robótica e das tecnologias conexas" 48 , na qual reforça a necessidade de um quadro regulamentar eficaz e harmonizado para a IA, baseado no direito da União, na Carta e no direito internacional em matéria de direitos humanos, aplicável, em particular, às tecnologias de alto risco, a fim de estabelecer normas iguais em toda a União e de proteger eficazmente os valores da União.

Em suma, as disposições do direito europeu continuarão a aplicar-se com as atualizações necessárias à transformação digital ${ }^{49}$, forçando um enquadramento legal europeu da IA, proposta que se tornará pública ao longo do primeiro semestre de 2021, durante a Presidência Portuguesa do Conselho da União Europeia, e que se espera, que Portugal venha a dar um contributo numa matéria tão relevante.

\section{UMA PROPOSTA LEGISLATIVA EUROPEIA PARA A INTELIGÊNCIA ARTIFICIAL BASEADA NO RISCO}

Os desafios da aplicação da IA são abissais, em especial para a privacidade e no âmbito da segurança, sendo o campo jurídico desafiado continuamente pelo caráter disruptivo. Assim, não custa recordar que o novo enquadramento legal da IA deve reforçar o componente ética e ao mesmo tempo oferecer confiança ${ }^{50}$. Nesse sentido, neste novo enquadramento legal da IA, defende-se que os aspetos já abrangidos pela legislação horizontal ou setorial existente, a exemplo dos dispositivos médicos, continuarão a ser regidos por esta legislação. 
Por um lado, alerta-se para os desafios em matéria de segurança e de responsabilidade, específicos dos cuidados de saúde E nessa medida deverão ser consideradas as implicações jurídicas dos sistemas de IA que fornecem informações médicas especializadas aos médicos, sistemas de IA que fornecem informação médica diretamente aos doentes e sistemas de IA que executam diretamente tarefas terapêuticas.

Por outro lado, a relação do ser humano com as chamadas novas tecnologias, traduz um ponto de inflexão em todas as áreas, com especial impacto ao nível da subjetividade, da responsabilidade, da memória, da privacidade e da autonomia. Desde a moral, a ética, a ciência, a economia e ao Direito estão a ser efetivadas alterações profundas. Com base nisso, o Parlamento Europeu enumerou "uma lista dos setores de alto risco e das utilizações ou finalidades que encerram um risco de violação dos direitos humanos e fundamentais e das regras de segurança, tais como: o emprego, a educação, saúde, transportes, energia, o setor público (asilo, migração, controlos nas fronteiras, sistema judicial e serviços da segurança social), a defesa e segurança, finanças, banca e seguros" ${ }^{51}$.

Torna-se oportuno advertir que os tratamentos e procedimentos médicos podem oferecer um alto risco ${ }^{52}$, sendo ainda mais acentuado quando por via da aplicação de IA se possa pôr em causa a privacidade do paciente, a confidencialidade dos dados sensíveis ( informação de saúde, ${ }^{53}$ e informação genética ${ }^{54}$ ), podendo daí resultar uma lesão, morte ou danos materiais ou imateriais de relevo, bem como outros agravos de natureza discriminatória.

Justifica-se a imposição de cautelas, de limites e de reservas sobre a aplicação da inteligência artificial e a sua utilização na obtenção de informação relativa a dados de saúde e por outro lado, força o legislador a regular designadamente sobre quem irá aceder às bases de dados dos pacientes, por quanto tempo e como se controla o acesso. É incontestável que se assiste a um desafio contínuo que se agudiza na medida em que as tecnologias se tornam mais invasivas, subtis, disruptivas e, em vista disso, torna-se evidente a necessidade de se pensar em limites éticos que possam assegurar o espaço vital e o mínimo existencial das populações afetadas.

A OCDE e várias organizações internacionais, v.g., têm alertado para esses riscos. A Comissão, nas suas várias comunicações, o Comité Europeu 
para a Proteção de Dados, nas suas diretivas, e a Comissão Nacional de Proteção de Dados, têm lançado alertas e esforçam-se por apresentar uma direção, que passa pela necessidade de uma avaliação de impacto sobre a proteção de dados, bem como a segurança do tratamento, para além da observância dos princípios da necessidade e da proporcionalidade. A este propósito, não se deve afastar nesta reflexão do ponto essencial da proteção dos dados, aspeto fundamental na construção de um sistema protetivo não somente tecnicamente adequado quanto juridicamente seguro e comprometido com a responsabilidade e a solidariedade. Aliás, a proteção de dados pessoais na qualidade de um direito humano e fundamental é elemento inafastável quando se trata de IA.

\section{EQUILÍBRIO ENTRE SEGURANÇA E PRIVACIDADE}

É inegável "que há um alinhamento dos países, com destaque entre os Estados-membros da União, em relação ao modo como enfrentam o problema da proteção de dados, em especial no que afeta à segurança e à transmissibilidade (CALDEIRA;SARLET, 2020, p. 260). A esse propósito, a "estratégia europeia para os dados" assume a confiança como elemento essencial de uma economia dos dados, ágil, atrativa, segura e dinâmica, capaz de melhorar as decisões e a vida de todos os seus cidadãos ${ }^{55}$.

Por sua vez, a "Estratégia sobre a Inteligência Artificial para a Europa" 56 assenta em um quadro regulamentar centrado no ser humano, alicerçado na Carta dos Direitos Fundamentais da União Europeia (CDFUE) e guiado por valores éticos e princípios aplicados à IA: direitos humanos, responsabilidade e transparência. Porém, se a necessidade de promover a segurança no tão desejado regresso à normalidade, tem ditado a restrição dos nossos direitos humanos e fundamentais, à luz do Direito Europeu e da CDFUE, o tratamento dos dados pessoais deve observar o respeito pelo conteúdo essencial dos direitos afetados, sendo certo que "o direito à proteção de dados pessoais não é absoluto (e) deve ser considerado em relação à sua função na sociedade e ser equilibrado com outros direitos fundamentais, em conformidade com o princípio da proporcionalidade." [Considerando 4 RGPD]. 
Sobre o tratamento dos dados relativos à saúde e dados genéticos, o RGPD remete para o n. 1 do artigo 9. do RGPD, que proíbe o tratamento dessa informação sem o consentimento informado do paciente, salvaguardas as exceções. Aí se prevê que o tratamento da informação de saúde seja efetuado por um profissional obrigado a sigilo, ou por outra pessoa sujeita ao dever de confidencialidade, devendo ser garantidas as medidas adequadas de segurança da informação. 0 dever de sigilo é igualmente aplicável a todos os titulares de órgãos e aos trabalhadores que, no contexto do acompanhamento, financeiro ou na fiscalização da atividade de prestação de cuidados de saúde, tenham acesso a dados relativos à saúde (CALDEIRA;SARLET, 2020, p. 239-40).

É razoável defender que o legislador ao apresentar uma proposta legislativa para a IA mantenha inalteradas as designações previstas no RGPD. No plano interno, a Lei n.ำ 12/2005, de 26 de janeiro, que regula a Informação genética pessoal e informação de saúde, atualizada pela Lei n. - 26/2016, de 22 de agosto, promoveu uma mudança paradigmática relativamente à titularidade dos dados pessoais de saúde. No seu artigo 3.․,

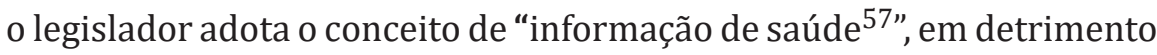
dos dados relativos à saúde, e consagra essa informação como sendo "propriedade" da pessoa a quem os dados dizem respeito. No plano do direito europeu secundário, mantêm-se os "dados relativos à saúde", definidos como dados pessoais relacionados com a saúde física ou mental de uma pessoa singular, incluindo a prestação de serviços de saúde que revelam informações sobre o seu estado de saúde (no 15 artigo 4.ำ RGPD).

Relativamente aos "dados genéticos" definem-se como dados pessoais relativos às características genéticas, hereditárias ou adquiridas, de uma pessoa singular que deem informações únicas sobre a fisiologia ou a saúde dessa pessoa singular e que resulta designadamente de uma análise de uma amostra biológica proveniente da pessoa singular em causa ( $\mathrm{n}^{\mathrm{o}}$ 15 artigo 4. RGPD). Tanto os dados relativos à saúde como os dados genéticos, são integrados nas categorias especiais de dados pessoais e por essa razão proíbe-se o seu tratamento, tal como decorre do n. $\stackrel{0}{1}$ do artigo 9. do RGPD, e no Considerando 51 RGPD.

Chama-se a atenção nesta altura, que não funcionando os sistemas de IA à margem da lei, as aplicações de IA devem não só ser coerentes 
com a legislação, como igualmente respeitar os princípios éticos e, nessa medida, assegurar eventuais danos decorrentes da sua aplicação. Contudo, implica questionar sobre as garantias que devem ser prestadas, pelos profissionais de saúde e pelas unidades do sistema de saúde relativamente à segurança da informação, quando em causa está o tratamento de dados de saúde, ensaios clínicos, medicina preventiva, diagnóstico médico, a prestação de cuidados ou tratamentos médicos e a gestão dos serviços de saúde (CALDEIRA;SARLET, 2020, p. 247). À luz do RGPD, deve-se mencionar, o tratamento desses dados são lícitos desde que efetuados por um profissional de saúde sujeito a sigilo médico ou por outra pessoa obrigada a segredo profissional de saúde e, desde que estejam garantidas medidas de segurança da informação (artigo 32.ำ).

0 consentimento do titular dos dados constitui um outro fundamento legítimo para o tratamento dos dados pessoais sensíveis, previstos por lei, quer no RGPD, quer em outro ato de direito da União ou de um Estado-membro, tal como se refere no considerando 40 do RGPD. Tratase de pedra angular na medida em que traça os novos contornos tanto da liberdade quanto da autonomia tendo por base a responsabilidade. Interessante trazer à luz que quando o tratamento de dados pessoais se fundamenta na monitorização de uma epidemia, bem como da sua propagação ou, em situações de emergência humanitária, em especial em situações de catástrofes naturais e de origem humana, será igualmente lícito o tratamento dos dados de saúde e de dados genéticos, mesmo sem consentimento do titular dos dados, tal como se extrai do considerando 46 do RGPD.

As derrogações ao $\mathrm{n}$ - 1 do artigo 9.을 do RGPD encontram-se previstas no 2 do mesmo artigo. Da leitura da g) do no 2 do artigo 9. - e do considerando 54 , consolida-se a certeza que as atividades de tratamento sobre a saúde são autorizadas por motivos de interesse público, não devendo esses dados serem tratados para outros fins e de acesso por parte de terceiros, a exemplo de companhias de seguros e bancos. Neste caso, admite-se poder incluir o tratamento de dados de saúde em tempo de pandemia, com recurso às tecnologias digitais por meio da criação da aplicação móvel $^{58}$, para o acesso a informações sobre o nível de circulação do vírus. 
Esta informação permite uma melhor avaliação da eficácia das medidas físicas de distanciamento e de confinamento, bem como uma melhor informação para o enfrentamento e o combate da COVID19. De qualquer modo, exigem-se critérios claros para diferenciar as várias aplicações de IA quando se trata de saber se são ou não "de alto risco". Porém, mesmo que uma aplicação de IA não seja qualificada como de alto risco, continua a estar inteiramente sujeita a regras da UE já existentes ${ }^{59}$.

Nessa conformidade e à luz do RGPD, os cidadãos devem ser claramente informados quando interagem com um sistema de IA e não com um ser humano. Os responsáveis pelo tratamento devem, no ato da coleta dos dados pessoais, fornecer aos titulares dos dados as informações suplementares necessárias para assegurar um tratamento equitativo e transparente da existência de tomadas de decisões automatizadas e de certas informações adicionais" (alínea f) do n.o 2 do artigo 13. RGPD) ${ }^{60}$.

Partindo do elevado risco que certas aplicações de IA representam para os cidadãos e para a sociedade, será necessário uma avaliação prévia e objetiva da conformidade, prevista no artigo 35. do RGPD, de modo a garantir o cumprimento de alguns dos requisitos obrigatórios às aplicações de alto risco ${ }^{61}$, nomeadamente a segurança do tratamento dos dados (artigo 32. ${ }^{\circ}$ RGPD), tal como foi mencionado anteriormente. Por sua vez, o controlo ex post deve ser facilitado por documentação adequada relativa à aplicação de IA em causa ${ }^{62}$. Em síntese e revisitados os principais postulados éticos que permitem a interpretação das regras jurídicas e reforçam a integração de lacunas da lei, importa salientar que é na tutela internacional dos direitos humanos e fundamentais, que se alicerçam os imperativos éticos geralmente formulados nos documentos de referência sobre a IA.

Aponta-se ainda que "a Ética carece da coercibilidade que só o Direito garante" (ANTUNES, 2020, p. 7). Daqui se extrai que as aplicações de IA devem não só ser coerentes com a legislação, como também respeitar os princípios éticos e assegurar eventuais danos decorrentes da sua aplicação. Do ponto de vista ético e jurídico, são necessárias métricas que respeitem os direitos humanos e fundamentais dos cidadãos, fomentando a relação de cooperação Homem/máquina a despeito da ideia de obsoletismo e de substituição. 
Em face disso, a percepção dos limites de empregabilidade da IA orienta-se para um panorama clarificado quanto à uma atual tessitura da condição de sujeito de Direito tendo em vista as inovações positivas, mas, consequentemente, atentando para os desafios advindos quanto ao controle e à vigilância que podem se prolongar e até se agudizar na medida em que, e.g., se flexibiliza na concretização da proteção de dados enquanto direito humano primordial.

\section{A CONSTRUÇÃO DE UMA UNIÃO EUROPEIA DA SAÚDE}

Na conferência dedicada à "Saúde Digital 2020-UE em Movimento", organizada pela Presidência alemã do Conselho da UE, em novembro de 2020, anunciou-se a intenção da UE trabalhar em conjunto para uma utilização dos dados de saúde de forma segura, e orientada para os doentes. Reafirmou-se a vontade de colaborar no domínio dos dados de saúde em todo o espaço europeu, para uma melhor saúde, melhor investigação e melhor desenho das políticas de saúde. Nessa mesma data, e no seguimento da "estratégia em matéria de dados", foi lançado a criação do "Espaço Europeu de Dados de Saúde", com propostas que vão no sentido de reforçar a sua estruturação e, sobretudo, a resposta às crises sanitárias ${ }^{63}$.

\section{BASE JURÍDICA}

A construção de uma União Europeia para a saúde encontra a base jurídica no artigo 168. do TFUE, que tutela um quadro regulamentar abrangente aplicável aos produtos e às tecnologias na área da medicina (medicamentos, dispositivos médicos e substâncias de origem humana), direitos dos doentes nos cuidados de saúde transfronteiriços e às ameaças sanitárias transfronteiriças graves. E, embora os Estados-membros sejam responsáveis pelo funcionamento dos seus sistemas de saúde, existem domínios específicos em que a UE pode legislar e outros em que a Comissão pode apoiar os esforços dos Estados-membros. 
O espaço europeu de dados de saúde permitirá o acesso aos dados de saúde ao abrigo de uma governança fidedigna com base em regras claras e, dessa forma, apoiará a livre circulação de serviços digitais de saúde. Com esse horizonte, até 2025, os pacientes de todos os Estadosmembros irão poder partilhar os seus dados com profissionais de saúde à sua escolha quando viajam para o estrangeiro. A Comissão Europeia pretende criar ainda uma "Agência de investigação e desenvolvimento avançados no domínio biomédico", bem como "Uma nova estratégia farmacêutica" que analisará a segurança da cadeia de abastecimento da Europa e garantirá o acesso dos cidadãos a medicamentos seguros, a preços acessíveis e de alta qualidade. ${ }^{64}$

A proposta regulamentar de criação do programa de ação da União no domínio da saúde para o período 2021-2027, prevê que o "Programa UE pela Saúde" contribua para a Carta dos Direitos Fundamentais da União Europeia, na medida em que irá melhorar o acesso a cuidados de saúde preventivos e o direito a se beneficiar de tratamento médico, nas condições estabelecidas pelas legislações e práticas nacionais. 0 novo programa está em consonância com o objetivo da Carta de ao assegurar um elevado nível de proteção da saúde humana na definição e execução de todas as políticas e ações da União."65

\section{A CONVERGÊNCIA ENTRE $O$ DIREITO DE PROPRIEDADE INTELECTUAL E OS DIREITOS HUMANOS}

Enfrentamento da pandemia implicou a sistematização da coleta, do armazenamento, da utilização de dados e das informações de saúde. Exigiu por outra banda o incremento global do conhecimento na área da saúde, à mobilização de centros de investigação, dos laboratórios, das universidades e das empresas. Esta partilha de informação sensível e de conhecimento em um esforço de convergência sem precedentes da comunidade científica global, potenciou formas inovadoras de responder às necessidades em termos de diagnóstico, de vacinas e de soluções terapêuticas de difícil obtenção com metodologias tradicionais. 
Esta crescente sistematização de dados e de informações em saúde humana, evoca diretamente o respeito pelos Direitos Humanos, Fundamentais e de Personalidade, destacando-se os direitos que emulam a privacidade no contexto atual, bem como os deveres de confidencialidade e, sobretudo, realçam a atenção crucial no âmbito da proteção à Propriedade Intelectual. Vale destacar que, em função da pandemia, jamais se viu tamanha profusão de dados e tampouco foi produzida de uma única vez tanta informação acerca desse tema, gerando um verdadeiro novo eldorado para a indústria farmacêutica.

0 regime internacional dos direitos da propriedade intelectual e os Direitos Humanos e Fundamentais evoluíram de uma forma independente. Porém, com o alargamento do âmbito de aplicação das patentes a áreas relacionadas com as necessidades básicas, como é a saúde, e em especial em um contexto pandémico, a ligação entre os dois domínios torna-se óbvia e direta, merecendo uma reflexão sobre o direito à saúde e a tutela de patentes, mormente no que toca aos medicamentos e às vacinas.

As patentes constituem monopólios que a sociedade está disposta a aceitar, por assumir que os benefícios das inovações na área da saúde serão superiores ao preço de monopólio que terão de suportar. Nessa medida, tal como defende a Organização Mundial da Saúde in "Public Health, Innovation and Intellectual Property Rights", justifica-se a atribuição da exclusividade por meio da patente por via dos incentivos ao investimento em I\&D; pelo potencial de transação de tecnologia especializada; pela divulgação de informações técnicas à sociedade e pela capacidade inovadora que apresenta, podendo ter acesso a financiamento de capital de risco, mediante o seu capital intelectual protegido (OMS, 2006, p. 19-21).

Perante a catástrofe sanitária mundial, não custa relembrar, corriase contra o tempo em busca de duas conquistas fundamentais: vacinas e aplicações móveis de vigilância epidemiológica, interoperáveis, que recorrendo à IA e ao uso dos big Data, fosse capaz de criar redes de vigilância epidemiológica em toda a Europa. 0 desenvolvimento e a disponibilização de vacinas eficazes e seguras apresentavam-se, como elementos essenciais para o controlo da pandemia, o que ditou um grande investimento na Ciência em ambiente colaborativo - collaborative research and development (R\&D), na designação inglesa. 
Para este ambiente colaborativo concorreu a harmonização internacional da propriedade industrial, alcançada mediante tratados por meio dos quais se procurou estabelecer uma proteção mínima para os direitos industriais, a exemplo dos que sumariamente apresentamos: Convenção de Paris para a Proteção da Propriedade Industrial (1883, com várias revisões);Tratado de Cooperação em Matéria de Patentes - PCT $(1970)^{66} ;$ e Acordo TRIPS (1994).

Em breve referência aos instrumentos internacionais sobre a proteção da propriedade industrial, infere-se que o pretendido é o incentivo à inovação, ao mesmo tempo, que se instituíram flexibilidades às disposições consagradas nos tratados, em prol da proteção dos direitos humanos, mediante a salvaguarda da saúde pública, do acesso aos medicamentos e às vacinas, sobretudo por parte dos países em desenvolvimento.

A Convenção de Paris para a Proteção da Propriedade Industrial afirma o princípio de solidariedade entre os Estados unionistas e faz prevalecer o direito unionista sobre os seus membros, por meio do qual se estabelece uma proteção mínima para os direitos da propriedade industrial. À luz desta Convenção, a apresentação de um pedido de patente de invenção num Estado Contratante confere, dentro de certo prazo, um direito de prioridades para apresentação do pedido nos outros Estados contratantes

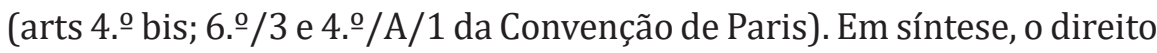
unionista edifica-se com base em três princípios fundamentais: o princípio da assimilação ou do tratamento nacional; o princípio da independência e o princípio do direito da prioridade unionista (MACHADO, 2017, p. 386-392).

0 Tratado de Cooperação em matéria de Patentes (PCT), é o instrumento multilateral da Organização Mundial da Propriedade Intelectual (OMPI/ WIPO) ${ }^{67}$, que integra mais de 150 Estados Contratantes, através do qual é permitido solicitar a proteção de uma invenção através de patente simultaneamente num grande número de países, depositando um único pedido de patente internacional (WIPO/OMPI, 2001, p. 4).

Por sua vez, o Acordo sobre os Aspetos dos Direitos de Propriedade Intelectual relacionadas com o comércio (TRIPS) ${ }^{68}$, veio reforçar a proteção da propriedade intelectual. 0 TRIPS assenta em 2 princípios gerais fundamentais: o princípio do tratamento nacional (artigo 3.․ㅡำ 1 ) e o do tratamento da nação mais favorecida (artigo $4 .^{\circ}$ ). Nos termos do 
Acordo TRIPS, todas as invenções devem poder ser protegidas por uma patente durante 20 anos, quer se trate de uma patente de produto um medicamento, ou a uma patente de processo, onde se inclui o método de produção de um medicamento. Para que, quer o produto, quer o processo, seja patenteável, a invenção tem de ser nova, constituir uma atividade inventiva e ter aplicabilidade industrial.

Ao instituir um sistema de proteção da Propriedade Intelectual, o Acordo TRIPS ${ }^{69}$ fá-lo à margem do sistema anteriormente existente, ou seja, à margem da Organização Mundial da Propriedade Intelectual (OMPI). Em síntese, o TRIPS contém um sistema que diverge do sistema da OMPI, quanto aos destinatários, ao conteúdo, à prevenção e à resolução de litígios, entre outros. 0 Acordo TRIPS protege as patentes farmacêuticas no artigo 33. , o qual determina que a duração da proteção auferida pela patente não terminará antes do termo de um período de vinte anos calculado a partir da data de depósito, isto é, da data da apresentação do respetivo pedido. 0 Acordo TRIPS consagra também uma flexibilidade na aplicação das suas disposições, consoante os interesses e as circunstâncias nacionais, mas salvaguardando-se a primazia da proteção da saúde pública.

A propósito, a Declaração de Doha da OMC sobre o Acordo TRIPS e Saúde Pública, vincula os temas de propriedade intelectual e da saúde pública, e estabelece a "primazia" das políticas de saúde pública sobre os direitos de propriedade intelectual. Nessa matéria, a Declaração representou um marco adicional na histórica das patentes farmacêuticas. Na prática, tendo em consideração as assimetrias entre países desenvolvidos e os países em vias de desenvolvimento, determina a Declaração de Doha (CULLET, 2003, p. 152) que os países em desenvolvimento ou em estágio de subdesenvolvimento recorram a acordos comerciais que lhes permitam importar os medicamentos, em tempo útil.

Atualmente, a eficácia do Acordo TRIPS é dificultada por acordos assinados fora do âmbito da OMC. Estes acordos são conhecidos como TRIPS-plus. Procedeu-se à celebração de Acordos TRIPS-plus, entre os EUA e os países da América Latina, acordos preferenciais de comércio, destacando especificamente o conteúdo TRIPS-plus das regras de proteção à propriedade intelectual contidas nos acordos. Essas regras ampliam e aprofundam o padrão mínimo obrigatório do TRIPS, produzindo 
efeitos importantes em políticas públicas vitais para o desenvolvimento socioeconómico desses países, dificultando o acesso a medicamentos junto aos Estados signatários.

No plano europeu, a Convenção sobre a Patente Europeia (1973, revista em 1978 e 2000) estabelece um processo unificado de concessão de patente para um ou mais Estados Contratantes, dando origem a vários direitos de propriedade intelectual independentes entre si (PINHEIRO, 2018, p. 630). Por último uma referência ao Regulamento (UE) no $1257 / 2012$, que enquadra a cooperação reforçada no domínio da criação da proteção unitária de patentes, que se tivesse sido aprovado, produziria efeitos em todo o território da União Europeia.

A patente unitária, de qualquer modo, foi colocada de novo na agenda política da União por Francisca Van Dunem, Ministra da Justiça de Portugal, aquando da primeira iniciativa da Presidência Portuguesa, intitulada: "A Metamorfose da Propriedade Intelectual na Era da Transição Digital"70. O sistema da patente unitária simplificará a conceção de patentes na União Europeia e criará um balcão único para as empresas, simplificando substancialmente a concessão de patentes na União Europeia ${ }^{71}$.

\section{O ECOSSISTEMA INDUSTRIAL E A TUTELA DA INOVAÇÃO: OS DIREITOS INDUSTRIAIS}

No plano europeu, a promoção da inovação e da criatividade, bem como o acesso ao conhecimento e à informação, são consagrados no direito europeu de propriedade intelectual, particularmente no artigo 118. ${ }^{\circ}$ do TFUE. Desse modo, o legislador europeu pretende assegurar uma proteção uniforme desses direitos em toda a União e incentivar a inovação ${ }^{72}$. Na prática, os direitos de propriedade intelectual no âmbito europeu são títulos exclusivos industriais predominantemente disciplinados por regulamentos. E, a consagração europeia dos títulos baseia-se no "primado da livre circulação de produtos e serviços no seio do espaço da UE"73.

Em 2020, a Europa definiu "Uma nova estratégia industrial para a Europa”, que foi apresentada pela Comissão Europeia na comunicação de 10 de março de $2020^{74}$, na qual demonstrou o empenho da Europa 
na investigação e na implantação de tecnologias em domínios como a IA, a tecnologia $5 \mathrm{G}$ e a análise de dados e de metadados.

De fato, a Europa ${ }^{75}$ pretende liderar o ecossistema industrial, contribuindo com as novas tecnologias emergentes para a sustentabilidade e a viabilidade da base industrial europeia. Enfatiza-se a importância de uma política de propriedade intelectual, como condição necessária para reforçar a soberania da Europa no domínio da tecnologia e promoção de condições de concorrência equitativas à escala mundial. Para tal, a Comissão Europeia apelou às políticas inteligentes em matéria de propriedade intelectual $^{76}$, de modo a garantir os ativos intangíveis, com especial destaque para os ativos industriais (as patentes), e, nessa medida, ajudar a determinar o valor de mercado e a competitividade das empresas.

A propriedade intelectual, na sua dimensão industrial, é definida pela Convenção da Organização Mundial da Propriedade Intelectual (OMPI/WIPO) ${ }^{77}$ como:

“a soma dos direitos relativos (...) às invenções em todos os domínios da
atividade humana, às descobertas científicas, aos desenhos e modelos
industriais, às marcas industriais, comerciais e de serviço, bem como às
firmas comerciais e denominações comerciais, à proteção contra a concor-
rência desleal e todos os outros direitos inerentes à atividade intelectual
nos domínios industrial, científico, literário e artístico".

A tutela dos direitos industriais, destarte, visa contribuir para a promoção da inovação tecnológica, a transferência e difusão da tecnologia e o bem-estar social e económico. São estes os objetivos que norteiam várias convenções e acordos internacionais, desde a Convenção de Paris para a Proteção da Propriedade Industrial (1883) ao Acordo sobre os Aspetos dos Direitos de Propriedade Intelectual relacionadas com o comércio-TRIPS (1994), em vigor.

Estas categorias de direitos industriais, envolvem a atribuição de direitos exclusivos de utilização de determinados bens imateriais, relativos à inovação ou à diferenciação empresarial e, as duas categorias proíbem todos as demais do uso desses bens. Contudo, apresentam diferenças quanto á sua função e ao regime. Assim, 
"enquanto os direitos relativos à tutela da inovação visam incentivar a criatividade nos domínios da técnica e da estética industrial (através da atribuição de exclusivos temporários de exploração), os grupos de sinais distintivos destinam-se a ordenar a concorrência no mercado (mediante a atribuição de sinais privativos de identificação dos produtos, dos serviços ou das empresas, de duração indefinidamente renovável. (SILVA, 2020, 15-6)"

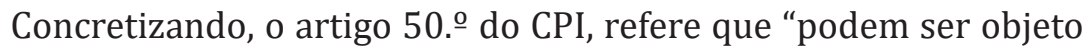
de patente as invenções novas, implicando atividade inventiva, se forem suscetíveis de aplicação industrial, mesmo quando incidam sobre um produto composto de matéria biológica, ou que contenha matéria biológica, ou sobre um processo que permita produzir, tratar ou utilizar matéria biológica" (n. 1). Podem obter-se patentes para quaisquer invenções, quer se trate de produtos ou processos, em todos os domínios da tecnologia, desde que essas invenções respeitem o que se estabelece no número anterior" (n. -2 ). Podem igualmente ser objeto de patente os processos novos de obtenção de produtos, substâncias ou composições já conhecidos" (no 3). Importância para a saúde pública ou para a defesa nacional”. Neste caso, "o titular de uma patente pode ser obrigado a conceder licença para a exploração da respetiva invenção" (artigo 11178).

\section{O PAPEL DA INDÚSTRIA FARMACÊUTICA: EQUILÍBRIO E EQUACIONAMENTO ENTRE CUSTOS E BENEFÍCIOS DE ATRIBUIÇÃO DE UMA PATENTE}

A indústria farmacêutica desempenha um papel relevante na sociedade, porquanto da produção e da comercialização de produtos que interferem diretamente na saúde. A saúde é um bem jurídico elevado à categoria de direito humano e fundamental, plasmado no artigo 64. da Constituição da República Portuguesa de 1976. Aí se encontra vertido não só um direito à proteção da saúde, mas também um dever de todos de promover e defendê-la.

0 setor da indústria farmacêutica enfrenta desafios relacionados com os ciclos de inovação, por constituírem processos morosos e muitos exigentes financeiramente (fig. 1), verificando-se com frequência a 
celebração de parcerias público-privadas (PPP), com Universidades e outras entidades públicas. Nesta matéria, a União Europeia está claramente em desvantagem face aos EUA, Japão e China, facilmente verificável pelo número de patentes apresentados por estes países.

A patente ${ }^{79}$ constitui um título que confere um direito exclusivo de exploração de um invento, título que se justifica pelo investimento financeiro que é efetuado em I\&D ${ }^{80}$.

A proteção dos direitos industriais opera por meio de requerimento de patente: internacional, europeia e nacional. Porém, para que haja lugar a uma tutela legítima, a invenção deve reunir três requisitos: novidade ${ }^{81}$, atividade inventiva ${ }^{82}$ e aplicação industrial ${ }^{83}$. A atribuição da patente a uma empresa farmacêutica, visa garantir a lealdade da concorrência, pela atribuição de direitos privativos sobre os diversos processos técnicos de produção de um medicamento. Ou seja, as patentes proporcionam aos seus titulares os meios jurídicos para impedir que outros reproduzam, utilizem ou vendam novas invenções, por 20 anos, e sob reserva de um conjunto de exceções.

Observamos anteriormente que as patentes constituem monopólios que a sociedade está disposta a aceitar, mas o equilíbrio e o equacionamento entre os custos e os benefícios de atribuição de uma patente dependem do grau de desenvolvimento dos países. Esta posição foi defendida pela Organização Mundial da Saúde (OMS) ${ }^{84}$.

Não é demasiado advertir que em recente estudo sobre a "Importância das patentes na área da saúde (medicamentos e vacinas)”, publicado em abril de 2020, pelo INPI - Instituto Nacional de Propriedade Industrial, observa-se que o atual cenário pandémico de COVID-19, tornou as inovações tecnológicas na área da saúde, ainda mais relevantes para a sociedade ${ }^{85}$. E, torna-se imperioso recordar que a atual conjuntura colocou por terra as posições acirradas em perspectiva unicamente voltada para a economia, gerando forçosamente uma abordagem ancorada na solidariedade, na responsabilidade e, sobretudo, na sustentabilidade. 


\section{AS PATENTES FARMACÊUTICAS E PRAZOS ESPECIAIS DE PROTEÇÃO}

A proteção por patente tem a duração máxima de 20 anos (artigo 100. CPI), podendo ser estendida por mais cinco anos, mediante determinadas condições e um certificado complementar de proteção $(\mathrm{CCP})^{86}$, instrumento que que vem ganhando cada vez importância no domínio da indústria farmacêutica (AGAPITO, 2015). Quando a patente atinge o limite de vigência, "cai" no domínio público, ou seja, a invenção deixa de estar protegida e, a partir dessa data, qualquer entidade pode explorar essa mesma invenção. Esta limitação temporal incentiva as empresas a introduzir os medicamentos no mercado o mais rapidamente possível e a desenvolver, de uma forma contínua, medicamentos inovadores.

A tutela do direito industrial por meio de patentes ou de certificado complementar de proteção é atribuída ao "medicamento de referência ou original"87. Os "medicamentos genéricos"88, que proporcionam aos doentes o acesso a um preço mais baixo, reduzindo também as despesas do Sistema Nacional de Saúde, surgem na fase de caducidade/extinção da tutela do medicamente original, acrescida da dilação de um CCP.

Em Portugal, v.g., constata-se que a entrada dos medicamentos genéricos ocorre em momento muito tardio, em virtude dos titulares de uma patente sobre um medicamento de referência se socorrem de vários instrumentos legais para retardarem a entrada de medicamentos genéricos no mercado, com o objetivo de restringir a concorrência e prorrogar o monopólio legal outorgado por esse direito de propriedade industrial. 0 fundamento utilizado pelas empresas produtoras de medicamentos inovadores prende-se com o grande investimento/risco realizado, por se tratar de uma atividade à qual está subjacente um esforço intelectual do inventor.

Inconteste uma dicotomia entre as empresas produtoras de medicamentos de referência e as empresas produtoras de medicamentos genéricos. Ainda que um medicamento genérico pressuponha a existência de um medicamento de referência, os interesses subjacentes às respetivas empresas produtoras de medicamentos de referência são 
distintos, promovendo inúmeras vezes obstáculos à comercialização de medicamentos genéricos.

Os obstáculos à comercialização e medicamento genéricos e as necessidades farmacêuticas não satisfeitas na Europa, levaram a Comissão a apresentar uma "Estratégia Farmacêutica para a Europa", no dia 24 de novembro de 2020, de modo a garantir o acesso dos doentes a medicamentos inovadores e a preços acessíveis, ao mesmo tempo, que promove a competitividade, a inovação e a sustentabilidade da indústria farmacêutica europeia. A estratégia possui quatro objetivos principais: garantir o acesso a medicamentos baratos para os doentes e responder a necessidades médicas (na área da resistência antimicrobiana, do cancro e das doenças raras, por exemplo); apoiar a competitividade, a inovação e a sustentabilidade da indústria farmacêutica da UE e o desenvolvimento de medicamentos de elevada qualidade, seguros, eficazes e mais ecológicos; melhorar os mecanismos de preparação e resposta a crises; e garantir uma presença europeia forte no mundo, ao promover um elevado nível das normas de qualidade, eficácia e segurança ${ }^{89}$.

A "Estratégia Farmacêutica para a Europa" nasce da necessidade de uma nova abordagem europeia que garante um setor farmacêutico forte, equitativo, competitivo e ecológico, que proporcione resultados aos doentes e que explore todo o potencial da transformação digital da saúde e dos cuidados de saúde impulsionada pelos avanços tecnológicos em domínios como a inteligência artificial e a modelização computacional ${ }^{90}$.

A Comissão Europeia reconhece o papel da proteção aos produtos e processos inovadores por meio de direitos de propriedade intelectual, contudo refere que a aplicação desses direitos, divergem de Estadomembro para Estado-membro, sobretudo no que se refere às patentes e aos certificados complementares de proteção ${ }^{91}$. Reconhece também, que as indústrias que utilizam a propriedade intelectual de forma intensiva, desempenham um papel essencial na economia da UE e oferecem à sociedade postos de trabalho sustentáveis ${ }^{92}$. Nessa medida, apresenta-se como prioritário a garantia de que os inovadores da UE tenham acesso a instrumentos de proteção rápidos, eficazes e a preços acessíveis, à medida que se elimina a fragmentação provocada pelos diferentes ordenamentos 
jurídicos. Para que tal aconteça, é necessário garantir o relançamento do sistema de patente unitária 9394.

\section{CONCLUSÕES FINAIS}

Em síntese, em uma altura em que se vive uma situação pandémica, urge uma releitura do catálogo dos direitos humanos e fundamentais já consolidados na maioria dos países ocidentais para empreender esforços globais para a estruturação de políticas de governança que estejam adaptadas ao atual desenvolvimento de programas e de algoritmos e que sejam concretizáveis quanto à sua aplicabilidade, transparência e auditabilidade, garantindo a proteção multinível da pessoa humana e, com isto, garantindo a consolidação dos regimes democráticos alinhados com uma perspectiva de cibersegurança a despeito de práticas de vigilantismo.

A Europa está empenhada em fazer avançar os progressos científicos, preservando uma certa liderança tecnológica, desde que as novas tecnologias estejam ao serviço de todos, melhorando as suas vidas e respeitando simultaneamente os seus direitos. Em rigor, a construção de uma União Europeia para a saúde não é indissociável do espaço europeu de dados de saúde. A saúde, mais especificamente, os dados produzidos nessa área são dados eminentemente sensíveis e, portanto, caracterizados como os mais valiosos para a era em que vivemos, do uso desenfreado das chamadas novas tecnologias, que se tornaram lugar comum na vidas das pessoas em geral, a despeito da sutileza, da disruptividade e da pervasividade.

A proteção de dados de saúde goza de uma posição preferencial quanto ao sistema protetivo que se torna lapidar e modelo para outros países na medida da atuação consciente da EU em favor da pessoa humana e da sua centralidade. A propósito, a projeção de um elemento ético imprescindível no contorno da atuação da ciência deve, de modo geral, ter uma firmeza a ponto de garantir um bem civilizaconal sem se tornar um obstáculo à inovação. A questão das patentes, nesses termos, ganha destaque em tempos pandémicos em que a sustentabilidade industrial 
não pode ser paga pelos dados dos pacientes e de demais pessoas que porventura se submetam a ensaios clínicos.

Destaque-se que a Comissão Europeia pretende criar uma Agência de investigação e de desenvolvimento avançados no domínio biomédico, bem como uma nova estratégia farmacêutica europeia que analisará a segurança da cadeia de abastecimento da Europa e garantirá o acesso dos cidadãos a medicamentos seguros, a preços acessíveis e de alta qualidade. Central neste novo panorama é a garantia do lançamento do sistema de patente unitária, um sistema que simplificará a concepção de patentes na União Europeia.

Alerta-se, nessa ordem, que a pandemia da COVID19 provocou um grande ponto de inflexão para a vida humana e, nesse sentido, para a UE, implicou a produção de um pensamento em rede em que além da busca pelo lucro devem ser envidados todos os esforços possíveis para pensar em uma perspectiva mais ampla e planetária, que vá além do presente nebuloso, e que crie um novo estar no mundo com uma base concreta de sustentabilidade, de coerência, de segurança e de responsabilização na proporção dos danos causados e dos ganhos obtidos.

\section{NOTAS}

1 COM(2020) 65, p. 2.

2 PARLAMENTO EUROPEU. Relatório sobre os direitos de propriedade intelectual para o desenvolvimento de tecnologias ligadas à inteligência artificial, 2.10.2020.

3 Portugal preside ao Conselho da União Europeia durante o primeiro semestre de 2021.

$4 \operatorname{COM}(2020) 64$ final, p.2.

5 A machine learning, técnica em que o computador "lê" previamente milhares de radiografias classificadas como normais ou com fracturas e aplica esse conhecimento aos novos exames. Esta técnica foi de resto já aplicada com sucesso no diagnóstico da retinopatia diabética (...) e cancro da pele. Segundo o médico especialista, a técnica diagnóstica, que combina dados informáticos e pensamento clínico, é relevante também para a precisão da deteção das fraturas, na medida que a aumenta significativamente, quando comparada apenas com a análise humana in (CARNEIRO, 2018).

6 A Presidência alemã do Conselho da União Europeia ( $2^{\circ}$ semestre de 2020), chegou a um acordo político provisório com os negociadores do Parlamento Europeu sobre a proposta de regulamento que estabelece o Horizonte Europa, o programa-quadro de investigação e inovação da UE para o período de 2021 a 2027.

7 Programa Europa Digital - o Conselho e o Parlamento Europeu chegaram a um acordo provisório no dia 14.12.2020 sobre um novo programa, o Europa Digital, que promoverá a implantação em larga escala de tecnologias de ponta, como a inteligência artificial e a cibersegurança, a fim de impulsionar a transformação digital das sociedades e economias europeias. 0 programa decorrerá 
durante o período de vigência do Quadro Financeiro Plurianual (QFP) para 2021-2027, sendo dotado de um orçamento no montante de 7588 milhões de euros.

$8 \operatorname{COM}(2020) 624$ Final.

$9 \operatorname{COM}(2020) 66$.

$10 \operatorname{COM}(2020) 65$.

11 A Comissão incumbiu a Agência da União Europeia para a Cibersegurança, ENISA, de preparar o esquema de certificação de cibersegurança da UE para redes 5G que ajudará a abordar os riscos relacionados com as vulnerabilidades técnicas das redes e a aumentar ainda mais a sua cibersegurança.

12 Proposta de Regulamento do Parlamento Europeu e do Conselho sobre um Mercado Único de Serviços Digitais “Lei dos Serviços Digitais", COM(2020) 825final, 15.12.2020. Atualiza a Diretiva sobre o Comércio Eletrónico, Diretiva 2000/31/CE, de 08.06.2000.

0 novo quadro proposto no DSA pretende reequilibrar os direitos e responsabilidades dos utilizadores, plataformas intermediárias e autoridades públicas e baseia-se nos valores europeus incluindo a liberdade de expressão e de informação (al. b) do artigo 26. e al. e) do artigo 37.. ), democracia (ponto (68) e (69) do preâmbulo) e igualdade e não discriminação (ponto (52), (63), (91) do preâmbulo, al. b) do artigo 26. ․ e al. e) do artigo 37.ํ). Por exemplo, as plataformas que atinjam mais de $10 \%$ da população da UE (45 milhões de utilizadores) serão consideradas como sendo de natureza sistémica e estarão sujeitas não apenas a obrigações específicas de controlo dos seus próprios riscos, nomeadamente regras para a remoção de bens, serviços ou conteúdos ilegais em linha, mas também a uma nova estrutura de supervisão. Este novo quadro de responsabilização propõe a existência de um conselho de Coordenadores de Serviços Digitais nacionais, com poderes especiais para a Comissão na supervisão de plataformas muito grandes, incluindo a capacidade de as sancionar diretamente.

13 Proposal for a Regulation of the European Parliament and of the Council on contestable and fair markets in the digital sector "Digital Markets Act", COM(2020) 842final,15.12.2020.

A proposta de DMA, vem no seguimento do Regulamento UE 2019/1150, de 20 de junho de 2019, e estabelece regras harmonizadas que definem e proíbem as práticas desleais dos $g a-$ tekeepers, plataformas com um número igual ou superior a 45 milhões de utilizadores, como a Amazon, Apple, Facebook, Google e Microsoft, e fornece um mecanismo de aplicação baseado em investigações de mercado. 0 mesmo mecanismo garantirá que as obrigações estabelecidas no regulamento sejam mantidas em dia na realidade digital em constante evolução.

14 JOUE. Regulamento (UE) 2016/679 do Parlamento Europeu e do Conselho, de 27.04.2016.

15 JOUE. Diretiva (UE) 2016/680, de 27.04.2016.

$16 \operatorname{COM}(2017) 10$ final.

17 JOUE. Recomendação (UE) 2020/518, da Comissão, de 8 de abril de 2020.

$18 \operatorname{COM}(2020) 690$ final.

19 EUR-LEX. Lista de documentos chave de saúde pública.

20 JOUE. Recomendação (UE) 2020/518 da Comissão de 8 de abril de 2020.

21 PARLAMENTO EUROPEU. Fichas temáticas sobre a União Europeia, 2021.

$22 \operatorname{COM}(2020) 245$ final.

23 SNS. Plano de Vacinação COBID-19, 3 de dezembro de 2020.

24 Idem ibidem.

25 A avaliação desse primeiro programa concluiu que era necessária uma abordagem mais horizontal e interdisciplinar no futuro, para que a ação da UE conseguisse criar valor acrescentado. Esta abordagem foi acolhida na conceção dos programas subsequentes, ou seja, o Programa de Saúde Pública da UE 2003-2008, o Programa de Saúde 2009-2013 e o Terceiro Programa de Saúde 2014-2020 e atual programa UE pela Saúde (2021-2027).

26 Os objetivos do programa EU4Health 2021-2027 passam por: i) reforçar o grau de preparação da UE para as principais ameaças sanitárias transfronteiriças: constituir reservas de material médico para situações de crise; criar uma reserva de profissionais de saúde e de peritos que possam ser mobilizados para responder a crises sanitárias em toda a UE; aumentar a vigilância das ameaças sanitárias; ii) reforçar os sistemas de saúde para que possam enfrentar epidemias, bem como os desafios a longo prazo, ao estimular: a prevenção de doenças e a promoção da saúde numa 
população envelhecida; a transformação digital dos sistemas de saúde; o acesso aos cuidados de saúde para os grupos vulneráveis; disponibilizar e tornar acessíveis os medicamentos e os dispositivos médicos, defender a utilização prudente e eficiente dos agentes antimicrobianos, bem como promover a inovação médica e farmacêutica e o fabrico mais ecológico.

27 PARLAMENTO EUROPEU. Relatório sobre os direitos de propriedade intelectual para o desenvolvimento de tecnologias ligadas à inteligência artificial, 2 de outubro 2020.

$28 \operatorname{COM}(2018) 795$ final.

29 INPI. Importância das patentes na área da saúde (medicamentos e vacinas), abril de 2020.

30 JOUE. Recomendação (UE) 2020/518, da Comissão, de 8 de abril de 2020.

31 Discurso da Presidente da Comissão Europeia no evento de apresentação do "Masters of Digital 2021", 4 de fevereiro de 2021.

$32 \operatorname{COM}(2020) 65$ final, p. 1.

$33 \operatorname{COM}(2020) 65$, p. 11e12.

$34 \mathrm{COM}(2020) 65, \mathrm{p} .22$.

35 Grupo Independente de Peritos de Alto Nível sobre a Inteligência Artificial. Orientações éticas para uma inteligência artificial, junho 2018, p. 6.

36 A OCDE defende um conjunto de princípios: crescimento inclusivo; desenvolvimento inclusivo; desenvolvimento sustentável e bem-estar; valores focados nos seres humanos e na justiça; transparência e explicabilidade; robustez; segurança e proteção e prestação de contas.

37 OCDE. "Recomendação do Conselho da Inteligência Artificial", aprovada em 22 de maio de 2019.

38 A OCDE integra países como a Alemanha, Áustria, Austrália, Bélgica, Canadá, Chile, Coreia do Sul, Dinamarca, Eslováquia, Eslovénia, Espanha, EUA, Estónia, Finlândia, França, Grécia, Hungria, Irlanda, Islândia, Israel, Itália, Japão, Letónia, Lituânia, Luxemburgo, México, Nova Zelândia, Noruega, Países Baixos, Polónia, Portugal, Reino Unido, República Checa, Suécia, Suíça e Turquia, tendo a Recomendação do Conselho da OCDE sobre Inteligência Artificial sido também subscrita pela Argentina, Colômbia, Costa Rica, Peru e Roménia, além de pelo Brasil, como referimos no início

39 "[...] a manifestação da única prova pela qual um sistema de valores pode ser considerado fundado humanamente e, portanto, reconhecido: esta prova é o consenso sobre a sua validade. Os jusnaturalistas falariam de "consenso omnium gentium" ou "humani generis". [até porque] "Não sei se percebemos até que ponto a Declaração Universal representa um novo facto na história, uma vez que, pela primeira vez na história, um sistema de princípios fundamentais de conduta humana foi livre e expressamente aceite, através dos respetivos governos, pela maioria dos homens vivos na Terra. Com esta declaração, um sistema de valores é (pela primeira vez na história) universal, não de princípio, mas de facto, uma vez que o consenso sobre a sua validade e a sua adequação ao destino da futura comunidade de todos os homens foi explicitamente declarado" (tradução nossa).

40 MASSENO, Manuel D. “Das Consequências Jurídicas da Adesão do Brasil aos Princípios da OCDE para a Inteligência Artificial, Especialmente em Matéria de Proteção de Dados”, 2020, p. 114.

41 "1 - Ação e supervisão humanas (Incluindo os direitos fundamentais, a ação humana e a supervisão humana); 2 - Solidez técnica e segurança (Incluindo a resiliência perante ataques e a segurança, os planos de recurso e a segurança geral, a exatidão, a fiabilidade e a reprodutibilidade); 3 - Privacidade e governação dos dados (Incluindo o respeito da privacidade, a qualidade e a integridade dos dados e o acesso aos dados); 4 - Transparência (Incluindo a rastreabilidade, a explicabilidade e a comunicação); 5 -Diversidade, não discriminação e equidade (Incluindo a prevenção de enviesamentos injustos, a acessibilidade e a conceção universal e a participação das partes interessadas); 6 -Bem-estar societal e ambiental (Incluindo a sustentabilidade e o respeito do ambiente, o impacto social, a sociedade e a democracia); 7 - Responsabilização (Incluindo a auditabilidade, a minimização e a comunicação dos impactos negativos, as soluções de compromisso e as vias de recurso)", in Grupo Independente de Peritos de Alto Nível sobre Inteligência Artificial (GPAN IA), Orientações éticas para uma inteligência artificial, 2019, p. 6.

42 Grupo Independente de Peritos de Alto Nível sobre Inteligência Artificial, Orientações éticas para uma inteligência artificial, p. 32 a 40.

43 Plataforma lançada em janeiro de 2019, que reúne algoritmos, ferramentas, conjuntos de dados e serviços para ajudar as organizações a aplicarem soluções de inteligência artificial. 
$45 \operatorname{COM}(2020) 65$, p. 1.

$46 \operatorname{COM}(2020) 65$, p. 2.

47 COM(2019)168 final.

48 PARLAMENTO EUROPEU. Resolução que contém recomendações à Comissão sobre o regime relativo aos aspetos éticos da inteligência artificial, da robótica e das tecnologias conexas, 20 de outubro de 2020.

$49 \operatorname{COM}(2020) 65$, p. 18.

50 PARLAMENTO EUROPEU. Resolução que contém recomendações à Comissão sobre o regime relativo aos aspetos éticos da inteligência artificial, da robótica e das tecnologias conexas, 20 de outubro de 2020.

51 PARLAMENTO EUROPEU. Resolução que contém recomendações à Comissão sobre o regime relativo aos aspetos éticos da inteligência artificial, da robótica e das tecnologias conexas, 20 de outubro de 2020.

52 Idem ibidem.

53 Entendemos por informação de saúde, "todo o tipo de informação direta ou indiretamente ligada à saúde, presente ou futura, de uma pessoa, quer se encontre com vida ou tenha falecido, e a sua história clínica e familiar" (artigo 2.ํ da Lei n.ำ 12/2005, de 26 de janeiro, Informação genética pessoal e informação de saúde, atualizada pela Lei n.ำ 26/2016, de 22 de agosto).

54 “1. A informação genética é a informação de saúde que verse as características hereditárias de uma ou de várias pessoas, aparentadas entre si ou com características comuns daquele tipo, excluindo-se desta definição a informação derivada de testes de parentesco ou estudos de zigotia em gémeos, dos estudos de identificação genética para fins criminais, bem como do estudo das mutações genéticas somáticas no cancro. 2 - A informação genética pode ser resultado da realização de testes genéticos por meios de biologia molecular, mas também de testes citogenéticos, bioquímicos, fisiológicos ou imagiológicos, ou da simples recolha de informação familiar, registada sob a forma de uma árvore familiar ou outra, cada um dos quais pode, por si só, enunciar o estatuto genético de uma pessoa e seus familiares. 3 - A informação genética reveste natureza médica apenas quando se destina a ser utilizada nas prestações de cuidados ou tratamentos de saúde, no contexto da confirmação ou exclusão de um diagnóstico clínico, no contexto de diagnóstico pré-natal ou diagnóstico pré-implantatório ou no da farmacogenética, excluindo-se, pois, a informação de testes preditivos para predisposições a doenças comuns e pré-sintomáticos para doenças monogénicas" (artigo 6.o Lei n. 12/2005, de 26 de janeiro, Informação genética pessoal e informação de saúde, atualizada pela Lei n. - 26/2016, de 28 de agosto).

$55 \operatorname{COM}(2020) 65$, p. 10.

56 A estratégia aborda três vertentes essenciais: o reforço da capacidade industrial e tecnológica da União Europeia; a integração da IA em toda a economia, garantido as mudanças socioeconómicas e a criação de um quadro ético e jurídico adequado, que coloque as pessoas no centro da IA.

57 O legislador define "informação de saúde" como um conceito macro onde cabem todas as informações relativas à saú de de uma pessoa, especificamente os dados registados nos processos clínicos, os resultados de análises e de outros exames subsidiários, das intervenções e dos diagnósticos, que são manejadas pelos profissionais de saúde na sua relação assistencial (Lei n.ํㅜ 12/2005, de 26 de janeiro, que regula a Informação genética pessoal e informação de saúde, atualizada pela Lei n.․ 26/2016, de 22/08).

58 Face a estes argumentos, aceita-se uma limitação da privacidade desde que:

A finalidade do tratamento seja clara; assumimos que a finalidade é a primeira justificação para a realização de um tratamento de dados. Acompanhamento quem defende que a finalidade constitui a trave mestra fundamental do regime jurídico da proteção de dados pessoais. Defendemos quer toda a recolha de dados sensíveis deve ter uma finalidade determinada explícita e legitima; 0 armazenamento da informação seja justificado. Exigimos uma adequação, pertinência e a limitação do tratamento desses dados às finalidades essenciais (minimização dos dados);

A Conservação apenas durante o tempo necessário às finalidades para as quais são tratadas (limitação da conservação); 
Exigência da aplicação de medidas técnicas e organizativas, de modo a que promova a salvaguarda dos direitos e liberdades do titular dos dados;

Õ tratamento dessa informação sensível se faça em segurança não permitindo o tratamento não autorizado (integridade e confidencialidade).

Seja igualmente defendido o direito ao apagamento dos dados pessoais, quando sejam superadas as razões que levaram ao seu tratamento;

Atribuição da responsabilidade pelo tratamento da informação;

Já não aceitamos, que as atividades de tratamento de dados constituam uma porta aberta para a discriminação, para a criação de perfis, incompatíveis com a finalidade ou a minimização dos princípios básicos, mas orientadores, previstos no art 5.ํ do RGPD. E como tal não abdicamos da Licitude, da Lealdade e da transparência do tratamento dos dados pessoais e em especial dos dados de saúde.

$60 \operatorname{COM}(2020) 65$, p. 22.

$61 \operatorname{COM}(2020) 65$, p. 25.

$62 \operatorname{COM}(2020) 65$, p. 26.

63 A União Europeia de Saúde inclui propostas como: reforçar a coordenação a nível da UE na eventualidade de ameaças sanitárias com dimensão transfronteiriça; rever os mandatos do Centro Europeu de Prevenção e Controlo das Doenças e da Agência Europeia de Medicamentos, a fim de reforçar a vigilância, a análise científica e as orientações antes e durante uma crise e criar uma nova agência da UE para a preparação biomédica. Disponível em: https://ec.europa.eu/info/ strategy/priorities-2019-2024/promoting-our-european-way-life/european-health-union_pt

$64 \operatorname{COM}(2020) 690$ final, p. 8.

$65 \operatorname{COM}(2020) 405$ final, p. 8.

66 WIPO/OMPI. Perguntas e Respostas sobre o PCT.

67 WIPO/OMPI. Perguntas e Respostas sobre o PCT.

68 O Acordo TRIPS prevê normas mínimas para a proteção de patentes, marcas comerciais, direitos autorais e outros direitos de propriedade intelectual.

69 Em Portugal, à data de aplicação do TRIPS (1 de janeiro de 1996), a matéria da propriedade industrial encontrava-se regulada, em termos de direito interno, pelo Código da Propriedade Industrial aprovado pelo Decreto-Lei n.. $16 / 95$, de 24 de janeiro, para entrar em vigor em 1 de junho de 1995(6), que substituíra o anterior Código da Propriedade Industrial, aprovado pelo Decreto n.. 30679, de 24 de agosto de 1940. No presente, a propriedade industrial é regulada pelo Decreto-Lei no 110/2018, de 10 de dezembro, que a prova o novo Código da Propriedade Intelectual, transpondo as Diretivas (UE)2015/2436 e (UE) 2016/943.

70 PRESIDÊNCIA PORTUGUESA DO CONSELHO DA UNIÃO EUROPEIA."The Intelellectual Property metamorphosis in the Age of Digital Transition", 11 de fevereiro de 2021.

$71 \operatorname{COM}(2020) 760$ final, p. 5.

72 PARLAMENTO EUROPEU. Relatório sobre os direitos de propriedade intelectual para o desenvolvimento de tecnologias ligadas à inteligência artificial, 2020.

73 MARQUES, Remédio. Comentário ao artigo no 118.ำ TFUE in Tratado de Lisboa, 2012.

$74 \operatorname{COM}(2020) 102, \mathrm{p} .4$.

$75 \operatorname{COM}(2020) 102$, p.2.

$76 \operatorname{COM}(2020) 102$, p.6.

77 A OMPI, atualizada na versão de Estocolmo (1967) e por força do TRIPS /OMC (1994), celebrada no âmbito das Nações Unidas, integra a Convenção de Paris (1883), o primeiro acordo internacional relativo à Propriedade Intelectual para a Proteção da Propriedade Industrial (CUP). Integra ainda a Convenção da União de Berna (1886), relativa à proteção das obras literárias e artísticas.

78 São os organismos nacionais ou regionais administradores de patentes, os responsáveis pela concessão das patentes na chamada fase nacional. Em Portugal, o processo de obtenção de patente, é da competência do Instituto Nacional de Propriedade Industrial. Por sua vez, a autorização de introdução no mercado (AIM) para a comercialização do medicamento é da 
competência da INFARMED. Passa ainda por um processo administrativo de fixação de um preço máximo de venda.

79 O processo de obtenção da patente de medicamento ou de processo, em Portugal é da competência do Instituto Nacional de Propriedade Industrial. Por sua vez, a autorização de introdução no mercado (AIM) para a comercialização do medicamento é da competência da INFARMED. Passa ainda por um processo administrativo de fixação de um preço máximo de venda.

80 A necessidade de grandes investimentos e o risco dos mesmos tem determinado a criação de parcerias. A Innovative Medicine Initiative (IMI) é uma parceria público privada entre uma empresa comum à União Europeia, representada pela Comissão, e a Federação Europeia das Associações e Indústrias Farmacêuticas, para a investigação na área da saúde, que se desenvolveu no âmbito programa-quadro de pesquisa e inovação - Horizonte 2020. 0 principal objetivo é acelerar o desenvolvimento de medicamentos com objetivos específicos, como: aumentando da taxa de sucesso de ensaios clínicos de novos medicamentos e vacinas e desenvolver novos marcadores biológicos para diagnosticar doenças e avaliar tratamentos.

81 O conceito de novidade implica que a invenção não está compreendida no estado da técnica (artigo $54^{\circ}, \mathrm{n} .{ }^{\circ}$ 1, do CPI). Por sua vez, o estado da técnica é constituído por tudo o que, dentro ou fora do País, foi tornado acessível ao público antes da data do pedido de patente, por descrição escrita ou oral, utilização ou qualquer outro meio (artigo 55ำ n.ำ 1, do CPI), incluindo o conteúdo de pedidos de patente e modelos de utilidade requeridos em data anterior à do pedido de patente mesmo não publicados (artigo 55으, n.․ㅡ 2, do CPI).

82 Considera-se que uma invenção implica atividade inventiva, se, para um perito na especialidade, não resultar ou não for dedutível, de maneira evidente, a partir do estado da técnica (artigo 54으, n. $\stackrel{\circ}{2}$, do CPI).

83 Considera-se que uma invenção é suscetível de aplicação industrial se o seu objeto puder ser fabricado ou utilizado em qualquer género de indústria ou na agricultura (artigo 54ํㅡ, n.․ 4, do CPI).

84 OMS. "Public Health, Innovation and Intellectual Property Rights", 2006, p. 22.

85 INPI. “Importância das patentes na área da saúde (medicamentos e vacinas)", abril de 2020.

86 O Certificado de Proteção para Medicamentos encontra-se previsto no Regulamento (UE) 2019/933 Do Parlamento Europeu e do Conselho de 20 de maio de 2019 que alterou o Regulamento (CE) n.o 469/2009, introduzindo algumas modificações a este regime, mais concretamente, introduziu exceções (ou waivers).

87 "Medicamento de referência", medicamento que foi autorizado com base em documentação completa, incluindo resultados de ensaios farmacêuticos, pré-clínicos e clínicos, segundo o artigo 3. ${ }^{\circ}$, n. 1 , al ii) do Decreto-Lei n.o 176/2006, atualizado pelo Decreto-Lei n.. $112 / 2019$, de 16 de agosto. 0 presente decreto-lei marca uma profunda mudança no sector do medicamento, designadamente nas áreas do fabrico, controlo da qualidade, segurança e eficácia, introdução no mercado e comercialização dos medicamentos para uso humano.

88 "Medicamento genérico", medicamento com a mesma composição qualitativa e quantitativa em substâncias activas, a mesma forma farmacêutica e cuja bioequivalência com o medicamento de referência haja sido demonstrada por estudos de biodisponibilidade apropriados (artigo 3.․ㅡ, noำ 1 , al vv do Decreto-Lei n.o 176/2006, atualizado pelo Decreto-Lei n.ํㅜ 112/2019, de 16 de agosto).

$89 \operatorname{COM}(2020) 761$ final.

$90 \operatorname{COM}(2020) 761$ final, p. 1 e 2.

$91 \operatorname{COM}(2020) 761$ final, p. 11.

$92 \operatorname{COM}(2020) 760$ final, p. 1.

$93 \mathrm{COM}(2020) 760$ final, p. 5.

$94 \operatorname{COM}(2020) 760$ final, p. 6. 


\section{REFERÊNCIAS BIBLIOGRÁFICAS}

AGAPITO, Inês. "O Certificado Complementar de Protecção para medicamentos" in Mestrado em Direito de Direito Empresarial Propriedade Industrial e Concorrência Desleal, Universidade Católica, 2015. Disponível em: http:// www.evaristomendes.eu/ficheiros/Ines_Agapito-O_Certificado_Complementar_ de_Proteccao_de_Medicamentos_(CCP).pdf

ANTUNES, Henrique Sousa. Direito e Inteligência Artificial, Universidade Católica Editora, em parceria com a Fundação Cupertino de Miranda, 2020.

CALDEIRA, Cristina. "O impacto ético e jurídico da aplicação das novas tecnologias na área da saúde" in: Direito da Sociedade do Conhecimento, Volume I, 2020, p. 222-253. Disponível em: https://bo.europeia.pt/content/ files/direito_da_sociedade_do_conhecimento-compactado.pdf

CALDEIRA, C. e SARLET, G. "O consentimento informado e a proteção de dados pessoais de saúde na Internet - uma análise das experiências legislativas de Portugal e do Brasil para a proteção integral da pessoa humana" in: Direito da Sociedade do Conhecimento, 2020, p. 256-280. Disponível em: https:// bo.europeia.pt/content/files/direito_da_sociedade_do_conhecimentocompactado.pdf

CALDEIRA, Cristina e FERNANDES, Márcia. “A partilha de dados pessoais sensíveis, dados epidemiológicos (COVID-19) e genéticos: aspectos jurídicos e bioéticos na perspetiva da União Europeia, Portugal e Brasil" in: Direito da Sociedade do Conhecimento, 2020, p. 322-375. Disponível em: https://bo.europeia.pt/ content/files/direito_da_sociedade_do_conhecimento-compactado.pdf

CAMPOS, António Correia de. Comentário ao artigo nำ 168. TFUE, in Tratado de Lisboa, anotado e comentado, Manuel Lopes Porto e Gonçalo Anastácio (Coord.), Editora Almedina, Coimbra, 2012.

CARNEIRO, António, V. "Inteligência Artificial em Saúde e os seus problemas", Revista Visão, 25 de agosto de 2018. Disponível em: https://visao.sapo.pt/ opiniao/bolsa-de-especialistas/2018-08-25-inteligencia-artificial-em-saudee-os-seus-problemas /

COECKELBERGH, Mark. AI ETHICS, The MIT Press Essential Knowledge series, London, 2020. 
COMiSSÃo EURopeia. Discurso da Presidente da Comissão Europeia no evento de apresentação do "Masters of Digital 2021", Bruxelas, dia 4 de fevereiro de 2021. Disponível em: https://ec.europa.eu/commission/ presscorner/detail/en/SPEECH_21_419

COMISSÃO EUROPEIA. Proposta de Regulamento do Parlamento Europeu e do Conselho sobre um Mercado Único de Serviços Digitais "Lei dos Serviços Digitais" e que altera a Diretiva 2000/31 / CE COM(2020)825 final, 2020/0361(COD), Bruxelas, 15 de dezembro de 2020. Disponível em: https:// eur-lex.europa.eu/legal-content/pt/ALL/?uri=COM:2020:825:FIN.

COMISSÃO EUROPEIA. Programa Europa Digital, Bruxelas, 14.12.2020. Disponível em: https://ec.europa.eu/digital-single-market/en/europeinvesting-digital-digital-europe-programme.

COMISSÃO EUROPEIA. Proposal for a Regulation of the European Parliament and of the Council on contestable and fair markets in the digital sector “Digital Markets Act", COM(2020)842 final, 2020/0374 (COD). Bruxelas, 15 de dezembro de 2020. Disponível em: https://eur-lex.europa.eu/legal-content/ EN/TXT/PDF/?uri=CELEX:52020PC0842\&from=pt

COMISSÃO EUROPEIA. Comunicação da Comissão do Parlamento Europeu, ao Conselho Europeu, ao Conselho, ao Comité Económico e Social Europeu e ao Comité das Regiões, "Estratégia Farmacêutica para a Europa”, COM(2020) 761 final, Bruxelas, 25 de novembro de 2020. Disponível em: https://eur-lex. europa.eu/legal-content/PT/TXT/PDF/?uri=CELEX:52020DC0761\&from=EN

COMISSÃO EUROPEIA. Comunicação da Comissão do Parlamento Europeu, ao Conselho Europeu, ao Conselho, ao Comité Económico e Social Europeu e ao Comité das Regiões, "Tirar pleno partido do potencial de inovação da UE Um plano de ação em matéria de propriedade intelectual para apoiar a recuperação e resiliência da UE", $\operatorname{COM(2020)} 760$ final, Bruxelas, 25 de novembro de 2020. Disponível em: https://ec.europa.eu/transparency/regdoc/ rep/1/2020/PT/COM-2020-760-F1-PT-MAIN-PART-1.PDF

COMISSÃO EUROPEIA. Comunicação "Programa de Trabalho da Comissão 2021, Uma União vital num mundo fragilizado", COM (2020)690 final, Bruxelas, 19.10.2020. Disponível em: https://eur-lex.europa.eu/resource. html?uri=cellar:91ce5c0f-12b6-11eb-9a54-01aa75ed71a1.0006.02/ DOC_1\&format=PDF 
COMISSÃO EUROPEIA. Preparação para as estratégias de vacinação contra a COVID-19 e a disponibilização das vacinas, COM (2020)680 final, Bruxelas, 15 de outubro de 2020. Disponível em: https://eur-lex.europa.eu/legal-content/ PT/TXT/?uri=CELEX:52020DC0680

COMISSÃO EUROPEIA. Plano de Ação para a Educação Digital (2021-2027), "Reconfigurar a educação e a formação para a era digital", COM (2020)624 final, Bruxelas, 30 de setembro de 2020. Disponível em: https://ec.europa.eu/ education/education-in-the-eu/digital-education-action-plan_pt

COMISSÃO EUROPEIA. Comunicação da Comissão ao Parlamento Europeu, ao Conselho Europeu, ao Conselho e ao Banco Europeu de Investimento, "Estratégia da UE para as vacinas contra a COVID-19", COM (2020)245 final, Bruxelas, 17 de junho de 2020. Disponível em: https://eur-lex.europa.eu/legalcontent/PT/TXT/PDF/?uri=CELEX:52020DC0245\&from=EN

COMISSÃO EUROPEIA. Proposta de regulamento do Parlamento Europeu e do Conselho de criação de um programa de ação da União no domínio da saúde para o período 2021-2027 e que revoga o Regulamento (UE) n.- 282/2014 “Programa UE pela Saúde", COM/2020/405 final, 28 de maio de 2020, p. 8. Disponível em: https://eur-lex.europa.eu/resource.html?uri=cellar:9b76a771a0c4-11ea-9d2d-01aa75ed71a1.0023.02/D0C_1\&format=PDF

COMISSÃO EUROPEIA. Comunicação da Comissão do Parlamento Europeu, ao Conselho Europeu, ao Conselho, ao Comité Económico e Social Europeu e ao Comité das Regiões, "Uma nova estratégia industrial para a Europa”, COM (2020)102 final, Bruxelas, 10 de março de 2020.

COMISSÃO EUROPEIA. Comunicação da Comissão do Parlamento Europeu, ao Conselho Europeu, ao Conselho, ao Comité Económico e Social Europeu e ao Comité das Regiões, “Construir o futuro digital da Europa”, COM (2020)67 final, Bruxelas, 19 de fevereiro de 2020. Disponível em: https://eur-lex.europa. eu/legal-content/PT/TXT/PDF/?uri=CELEX:52020DC0067\&from=EN

COMISSÃO EUROPEIA. A European strategy for data, COM(2020)66 final, Bruxelas, 19 de fevereiro de 2020. Disponível em: https://ec.europa.eu/info/ sites/info/files/communication-europeanstrategy-data-19feb2020_en.pdf 
COMISSÃO EUROPEIA. Livro Branco sobre a inteligência artificial - uma abordagem europeia virada para a excelência e a confiança, COM (2020)65 final, Bruxelas, 19 de fevereiro de 2020. Disponível em: https://ec.europa.eu/ info/sites/info/files/commission-white-paper-artificial-intelligence-feb2020_ pt.pdf

COMISSÃO EUROPEIA. Relatório sobre as implicações em matéria de segurança e de responsabilidade decorrentes da inteligência artificial, da Internet das coisas e da robótica, COM (2020)64final, Bruxelas, 19 de fevereiro de 2020. Disponível em: https://eur-lex.europa.eu/legal-content/PT/ TXT/PDF/?uri=CELEX:52020DC0064\&from=en

COMISSÃO EUROPEIA. Comunicação sobre "As regras de proteção de dados como instrumento gerador de confiança dentro e fora da UE - ponto da situação", COM(2019)374 final, Bruxelas, 24 de julho de 2019. Disponível em: https://eur-lex.europa.eu/legalcontent/PT/TXT/PDF/?uri=CELEX:52019DC0 $374 \&$ from $=$ EN

COMISSÃO EUROPEIA. Comunicação sobre "Aumentar a confiança numa inteligência artificial centrada no ser humano" COM(2019)168 final, Bruxelas, 8 de abril de 2019. Disponível em: https://eurlex.europa.eu/legalcontent/PT/TXT/PDF/?uri=CELEX:52019DC0168\&from=EN

COMISSÃO EUROPEIA. Comunicação sobre "Plano Coordenado para a Inteligência Artificial", COM(2018)795 final, 251 Bruxelas, 7 e dezembro de 2018. Disponível em: https://ec.europa.eu/transparency/regdoc/rep/1/2018/ PT/COM-2018-795-F1-PT-MAIN-PART-1.PDF

COMISSÃO EUROPEIA. Grupo Independente de Peritos de Alto Nível sobre a Inteligência Artificial. Orientações éticas para uma inteligência artificial, junho 2018. Disponível em: https://ec.europa.eu/digital-single-market/en/ high-level-expert-group-artificial-intelligence

COMISSÃO EUROPEIA. Comunicação da Comissão do Parlamento Europeu, ao Conselho Europeu, ao Conselho, ao Comité Económico e Social Europeu e ao Comité das Regiões, "Inteligência artificial para a Europa”, COM (2018)237 final, Bruxelas, 25 de abril de 2018. Disponível em: https://ec.europa.eu/ transparency/regdoc/rep/1/2018/PT/COM-2018-237-F1-PT-MAIN-PART-1.PDF

COMISSÃO EUROPEIA. Proposta de Regulamento do Parlamento Europeu e do Conselho relativo ao respeito pela vida privada e à proteção dos dados 
pessoais nas comunicações eletrónicas e que revoga a Diretiva 2002/58/ CE (Regulamento relativo à privacidade e às comunicações eletrónicas), Bruxelas, COM (2017) 10 final, de 10 de janeiro de 2017. Disponível em: https:// eur-lex.europa.eu/legal-content/PT/TXT/PDF/?uri=CELEX:52017PC0010\&f rom $=\mathrm{EN}$

CULLET, Philippe. "Patents and medicines: the relationship between TRIPS and the human right to health" in International Affairs 79, I (2003), 139-160. Disponível em: https://library.fes.de/libalt/journals/swetsfulltext/17639153.pdf

INPI- INSTITUTO NACIONAL DE PROPRIEDADE INDUSTRIAL. "Importância das patentes na área da saúde (medicamentos e vacinas)", abril de 2020. Disponível em: https://inpi.justica.gov.pt/Portals/6/PDF\%20INPI/ Not\%C3\%ADcias\%20-\%20ficheiros\%20de\%20apoio/Import\%C3\%A2ncia\%20 das $\% 20$ patentes $\% 20$ na $\% 20 \%$ C3\%A1rea $\% 20$ da $\% 20$ sa $\%$ C3\%BAde $\% 20$ (medicamentos\%20e\%20vacinas).pdf?ver=2020-04-26-122645-213

JOUE -JORNAL OFICIAL DA UNIÃO EUROPEIA. Carta dos Direitos Fundamentais da União Europeia. (JOUE no C-364/1). Bruxelas, 10.12.2000. Disponível em: http://www.europarl.europa.eu/charter/pdf/text_pt.pdf.

JOUE - JORNAL OFICIAL DA UNIÃO EUROPEIA . Diretiva (UE) 2016/680, de 27.04.2016. relativa à proteção das pessoas singulares no que diz respeito ao tratamento de dados pessoais pelas autoridades competentes para efeitos de prevenção, investigação, deteção ou repressão de infrações penais ou execução de sanções penais, e à livre circulação desses dados, e que revoga a Decisão-Quadro 2008/977/JAI do Conselho. Disponível em: https://eur-lex.europa.eu/legal-content/PT/TXT/PDF/?uri=CELEX:32016L0 680\&from $=\mathrm{PT}$

JOUE - JORNAL OFICIAL DA UNIÃO EUROPEIA. Diretiva 2011/24/UE do Parlamento Europeu e do Conselho, de 9.03.2011, relativa ao exercício dos direitos dos doentes em matéria de cuidados de saúde transfronteiriços (JO L 88), Bruxelas, de 4.4.2011 252.

JOUE - JORNAL OFICIAL DA UNIÃO EUROPEIA. Recomendação (UE) 2020/518, da Comissão, de 8 de abril de 2020, relativa a um conjunto de instrumentos comuns a nível da União com vista à utilização de tecnologias e dados para combater a crise da COVID-19 e sair da crise, nomeadamente no respeitante às aplicações móveis e à utilização de dados de mobilidade anonimizados, 
Bruxelas, 14.04.2020. Disponível em: https://eur-lex.europa.eu/legal-content/ PT/TXT/PDF/?uri=CELEX:32020H0518\&from=PT

JOUE - JORNAL OFICIAL DA UNIÃO EUROPEIA . Regulamento (UE) 2016/679, do Parlamento Europeu e do Conselho, de 27 de abril de 2016, Resolução do Conselho de Ministros n.o 41/2018 publicada em Diário da República, 1. ${ }^{\text {a }}$ série - N.o 62 - 28 de março de 2018. http://www.sg.pcm.gov.pt/ media/33586/02.pdf. Ratificação do Regulamento (UE) 2016/679, do Parlamento Europeu e do Conselho, de 27 de abril de 2016. relativo à proteção das pessoas singulares no que diz respeito ao tratamento de dados pessoais e à livre circulação desses dados e que revoga a Diretiva 95/46/CE (Regulamento Geral sobre a Proteção de Dados) (JO L 119), Bruxelas, 4.5.2016. Disponível em: http://www.sg.pcm.gov.pt/media/33583/01pdf_dados.pdf

JOUE - JORNAL OFICIAL DA UNIÃO EUROPEIA. Regulamento (UE) 2019/933 do Parlamento Europeu e do Conselho de 20 de maio de 2019 que altera o Regulamento (CE) n.o 469/2009 relativo ao certificado complementar de proteção para os medicamentos (L 153/1), Bruxelas, 11 de junho de 2019. Disponível em: https://eur-lex.europa.eu/legal-content/PT/TXT/PDF/?uri=C ELEX:32019R0933\&from=EN

JOUE - JORNAL OFICIAL DA UNIÃO EUROPEIA. Tratado da União Europeia (Versão Consolidada), C-326/13, Bruxelas, 26.10.2012. Disponível em: http:// eurlex.europa.eu/LexUriServ/LexUriServ.do?uri=0J:C:2012:326:0013:0046: PT:P DF.

MACHADO, João Baptista. Lições de Direito Internacional Privado, 3ํㅡ Edição atualizada (reimpressão), Almedina, Coimbra, 2017, p. 386-392.

MARQUES, Remédio. Comentário ao artigo nํㅜ 118. TFUE in Tratado de Lisboa, Manuel Lopes Porto e Gonçalo Anastácio (Coord.), Almedina, Coimbra, 2012.

MARTINO, A. Anselmo. "Logic, Informatics, Artificial Intelligence And Technology In Law: History And Challenges" in Law, Tecnologhy and Innovation, V.II. Insights on Atificial Intelligence and the Law, Expert Editora Digital, Leonardo Parentoni e Renato César Cardoso (Org.), 2020, p.28-48.

MASSENO, Manuel D. "Das Consequências Jurídicas da Adesão do Brasil aos Princípios da OCDE para a Inteligência Artificial, Especialmente em Matéria de Proteção de Dados", Revista Campo Jurídico, barreiras-BA v.8 n.1, p.113-122 julho-dezembro, 2020. 
OMS-ORGANIZAÇÃO MUNDIAL DA SAÚDE "Public Health, Innovation and Intellectual Property Rights", 2006, p.19, 20 e 21. Disponível em: https://www. who.int/intellectualproperty/documents/thereport/ENPublicHealthReport. pdf?ua $=1$

OCDE-ORGANIZAÇÃO PARA A COOPERAÇÃO E DESENVOLVIMENTO ECONÓMICO. "Recomendação do Conselho da Inteligência Artificial", aprovada em 22 de maio de 2019. Disponível em: https://legalinstruments. oecd.org/en/instruments/OECD-LEGAL-0449.

PARLAMENTO EUROPEU. Relatório sobre os direitos de propriedade intelectual para o desenvolvimento de tecnologias ligadas à inteligência artificial (2020/2015(INI), 2 de outubro 2020. Disponível em: https://www. europarl.europa.eu/doceo/document/A-9-2020-0176_PT.html

PARLAMENTO EUROPEU. Resolução do Parlamento Europeu, de 20 de outubro de 2020, que contém recomendações à Comissão sobre o regime relativo aos aspetos éticos da inteligência artificial, da robótica e das tecnologias conexas, P9TA(2020)0275. Disponível em: https://www.europarl. europa.eu/doceo/document/TA-9-2020-0275_PT.html

PARLAMENTO EUROPEU. Resolução de 16.02.2017, que contém recomendações à Comissão sobre disposições de Direito Civil sobre Robótica (2015/2103(INL). Disponível em: https://www.europarl.europa.eu/ doceo/document/TA-8-2017-0051_PT.html\#title1

VICENTE, Dário Moura. "Inteligência Artificial e Iniciativas Internacionais", in Inteligência Artificial \& Direito, Coordenação Manuel Lopes Rocha e Rui Soares Pereira; editora Almedina, Coimbra, 2020, p.93-105.

VICENTE, Dário Moura . Fichas temáticas sobre a União Europeia, 2021. Disponível em: www.europarl.europa.eu/factsheets/pt

PINHEIRO, Luís de Lima. Direito Internacional Privado, Volume II - Direito de Conflitos - Parte Especial, 4ª edição refundada, Almedina, Coimbra, 2018, p. 630 . 
PRESIDÊNCIA PORTUGUESA DO CONSELHO DA UNIÃO EUROPEIA. "The Intelellectual Property metamorphosis in the Age of Digital Transition", de 11 de fevereiro de 2021. Disponível em: https://www.2021portugal.eu/pt/ noticias/a-metamorfose-da-propriedade-intelectual-na-era-da-transicao-digital/

SILVA, Pedro Sousa e. Direito Industrial, 2ª edição, Editora Almedina, Coimbra, 2020.

SNS-SERVIÇO NACIONAL DE SAÙDE. Plano de Vacinação COVID-19, 3 de dezembro de 2020. Disponível em: https://www.sns.gov.pt/wp-content/ uploads/2019/06/PlanoVacinacaoCovid_19.pdf

WIPO/OMPI-WORLD INTELLECTUAL PROPERTY ORGANIZATION. Perguntas e Respostas sobre o PCT. Disponível em: https://www.wipo.int/export/sites/ www/pct/pt/basic facts/faqs about the_pct.pdf

WIPO/OMPI-WORLD INTELLECTUAL PROPERTY ORGANIZATION. ASSEMBLIES OF THE MEMBER STATES OF WIPO Thirty-Sixth Series of Meetings Geneva, September 24 to October 3, 2001, A/36/14, 6 de agosto de 2001, p. 4. Disponível em: https://www.wipo.int/edocs/mdocs/govbody/en/a_36/a_36_14.pdf

CONSTITUIÇÃO DA REPÚBLICA PORTUGUESA, de 1976. Decreto-Lei n.o 176/2006, de 30 de agosto, atualizado pelo Decreto-Lei n.o 112/2019, de 16 de agosto, estabelece o regime jurídico dos medicamentos de uso humano, transpondo a Diretiva n.o 2001/83/CE do Parlamento Europeu e do Conselho, de 6 de novembro de 2006.

CONSTITUIÇÃO DA REPÚBLICA PORTUGUESA, de 1976. Decreto-Lei no 110/2018, de 10 de dezembro, que a prova o novo Código da Propriedade Intelectual, transpondo as Diretivas (UE)2015/2436 e (UE) 2016/943.

PROCURADORIA-GERAL DISTRITAL DE LISBOAL. Lei n.o 26/2016, de 28 de agosto atualizada pela Lei no 33/2020, de 12 de agosto, Informação administrativa nominativa

PROCURADORIA-GERAL DISTRITAL DE LISBOAL. Lei n.o 12/2005, de 26 de janeiro, Informação genética pessoal e informação de saúde, atualizada pela Lei n.o 26/2016, de 28 de agosto

Recebido em: 29-8-2021

Aprovado em: 


\section{Gabrielle Bezerra Sales Sarlet}

Pós-Doutora em Direito pela Universidade de Hamburgo- Alemanha e igualmente pela PUCRS. Doutora em Direito pela Universidade de Augsburg- Alemanha com tese validada pelo PPGD- UFGRS. Mestre em Direito pela Universidade Federal do Ceará- UFC. Graduação em Direito pela Universidade Federal do CearáUFC. Advogada. Pesquisadora visitante e bolsista do Max-Planck-Institut für ausländisches und internationales Privatrecht - Hamburg- Alemanha (2018), Professora do curso de graduação e no PPGD em Direito na PUCRS- Pontifícia Universidade Católica do Rio Grande do Sul. Coordenadora do núcleo de estudos e pesquisas em Direito e Literatura na Escola Superior da Magistratura do Rio Grande do Sul (AJURIS) e do Grupo de Proteção de dados juntamente com a Professora Dra. Regina Ruaro na PUC-RS. Integrante do grupo de estudos e pesquisas em Direitos Fundamentais do PPGD da PUCRS e do Grupo de pesquisa em governança cooperativa, compliance, e proteção de dados vinculado ao CNPQ e homologado pela Universidade Presbiteriana Mackenzie - SP. Professora visitante e pesquisadora no Lehrstuhl für Bürgerliches Recht, Arbeits- und Handelsrecht sowie Rechtsphilosophie - Universidade de Augsburg- Alemanha. Especialista em Neurociências e ciências do comportamento na PUCRS e é Professora dos Cursos de Especialização em Direito Público e Direito de Família da PUCRS. Pesquisadora colaboradora no projeto em rede internacional PUCRS, Alemanha, Espanha e Portugal sobre Proteção de Dados e Saúde e no Projeto sobre Ações Afirmativas na América Latina, Inglaterra e África do Sul, parceria UNOESC, PPGDPUCRS, TALCA / Chile, Universidade de Midlesex /Londres. Participa como pesquisadora do Projeto Religious Beliefs and the Social Brain: Towards a Neuroscience-Engaged Theology John Templeton Foundation vinculado ao PPG de Filosofia sob a supervisão do Prof Dr. Nythamar de Oliveira. Autora de livros em Direito Constitucional e em Bioética publicadas pela NOMOS Verlag (Alemanha) e pela Manole (SP), bem como de dezenas de capítulos de livros e artigos científicos no Brasil e no exterior. Palestrante e participante em Bancas examinadoras em eventos no Brasil e no exterior. Coordenadora do curso de especialização em Direito Digital na PUCRS.

E-mail: gabriellebezerrasales@gmail.com

\section{Cristina Maria de Gouveia Caldeira}

Investigadora de Pós-doutorado da Faculdade de Ciências Sociais e Humanas da Universidade Nova de Lisboa, na área da Propriedade Intelectual. Doutorado em Direito na especialidade de em Ciências Jurídicas e Políticas pela Universidade Autónoma Lisboa (UAL) e o Programa Doutoral em Ciência Política na especialidade de políticas públicas,Universidade Católica Portuguesa, Lisboa. Mestre em Economia Internacional pelo ISEG - Lisbon School of Economics and Management, Universidade de Lisboa. Graduação em Direito e graduação em Relações Internacionais pela UAL. Foi Vice-Reitora do Instituto Universitário 
de Arte Design e Empresa (IADE), Lisboa. Bolseira da Fundação Gulbenkian na Universidade de Oxford, St Antony?s College. Colabora no Laboratório de Bioética no Hospital de Clínicas (RS Brasil), como investigadora na área de proteção de dados biomédicos. Articulista, autora de vários artigos em Propriedade intelectual e coautora de vários diplomas legais, incluindo a proposta de lei portuguesa sobre a proteção de dados pessoais. Docente universitária e assessora jurídica da Reitoria da Universidade Europeia, em Lisboa e participa em várias instituições internacionais Pontifícia Universidade Católica de Porto Alegre; Ajuris - Escola Superior da Magistratura de Porto Alegre, e Escola de Artes, Ciências e Humanidades da Universidade de S. Paulo, Brasil. Desempenhou funções de Adjunta da Secretária de Estado do Ministério da Ciência, Tecnologia e Ensino Superior de Portugal entre 2015 e 2018.

E-mail: gabriellebezerrasales@gmail.com

Pontifícia Universidade Católica do Rio Grande do Sul, PUCRS, Brasil.

Av. Ipiranga, 6681 - Partenon,

CEP: 90619-900 - Porto Alegre - RS, 